\title{
Proteomic profiling of pathological and aged skeletal muscle fibres by peptide mass fingerprinting (Review)
}

\author{
PHILIP DORAN, PAMELA DONOGHUE, KATHLEEN O'CONNELL, JOAN GANNON and KAY OHLENDIECK
}

Department of Biology, National University of Ireland, Maynooth, County Kildare, Ireland

Received November 9, 2006; Accepted December 11, 2006

\begin{abstract}
In contrast to the traditional biochemical study of single proteins or isolated pathways in health and disease, technical advances in the high-throughput screening of peptides by mass spectrometry have established new ways of identifying entire cellular protein populations in one swift analytical approach. This review discusses the recent progress in the biochemical analysis of skeletal muscle extracts and outlines the mass spectrometry-based proteomics approach for studying muscle tissues in normal and pathobiochemical processes using peptide mass fingerprinting. Individual topics covered include the most commonly inherited muscle disease, X-linked muscular dystrophy, the physiological process of fast-to-slow fibre transformation, and the role of fibre degeneration in age-related muscle wasting. Recent proteomic profiling studies of dystrophic muscles have revealed new disease markers in dystrophin-deficient fibres, such as adenylate kinase, the $\mathrm{Ca}^{2+}$-binding protein regucalcin and the small heat shock protein cvHSP. Since these muscle proteins are of low abundance, they have not previously been identified as biomarkers of muscular dystrophy, illustrating the increased sensitivity of modern mass spectrometric techniques. This review outlines comparative proteomic techniques that employ conventional labeling methods, such as Coomassie- or silver-staining. In addition, the most advanced proteomic screening approach currently available, fluorescence difference in-gel electrophoresis, is described and its potential for studying muscle proteomes is critically examined. As an alternative suggestion, the two-dimensional analysis of different protein samples separated in parallel on
\end{abstract}

Correspondence to: Professor Kay Ohlendieck, Department of Biology, National University of Ireland, Maynooth, County Kildare, Ireland

E-mail:kay.ohlendieck@nuim.ie

Abbreviations: DIGE, difference in-gel electrophoresis; ESI, electrospray ionization; MALDI, matrix-assisted laser desorption ionization; MS, mass spectrometry; ToF, time of flight; 2-D, twodimensional; PMF, peptide mass fingerprinting

Key words: biomarker, mass spectrometry, muscular dystrophy, peptide mass fingerprinting, proteomics, skeletal muscle aging a single second dimension gel is introduced and the usefulness of this technique for direct comparative investigations is explained. The potential of studying protein complex formation by intraproteomics, estimating the composition of subcellular fraction by subproteomics, and analyzing total muscle protein extracts by mass spectrometry-based proteomics, is enormous. Proteomics is one of the most promising new analytical ways of comparing large muscle protein complements and has the potential to decisively improve modern biochemical and biomedical research into neuromuscular disorders.

\section{Contents}

1. Introduction

2. Mass spectrometry-based proteomics

3. Biomarker identification and comparative proteomics

4. Skeletal muscle proteomics

5. Comparative proteomic analysis of muscular dystrophy

6. Proteomic profiling of sarcopenia of old age

7. Proteomics of skeletal muscle transformation

8. Future perspectives

\section{Introduction}

The availability of mass spectrometry (MS)-based proteomics for the large-scale screening of proteins has decisively enhanced the research capabilities of the modern biochemical laboratory (1). In contrast to the traditional biochemical approach of studying individual peptide species, isolated protein complexes or functionally linked groups of biomolecules, technical advances in the high-throughput MS screening of peptides now enable bioresearchers to identify entire protein complements (2-9). Although 2-D gel electrophoretic separation techniques represent the most frequently chosen separation strategy for the proteomics of soluble components (10), insoluble membrane proteins can also be studied using liquid chromatography methodology (11). Since post-translational modifications play an essential role in protein sorting and function, the characterisation of protein modifications has also been intensively studied by modern MS-based proteomics (12-14). Hence, proteomic profiling currently represents the most powerful tool for the fast identification of novel disease markers that are involved in 
neuromuscular disorders (15) and age-dependent muscle wasting (16). Based on initial proteomic data, new biomarkers can then be characterised in detail by standard biochemical, physiological and cell biological methods, and their potential for improving diagnostic procedures and/or therapeutic approaches can be evaluated.

A general hierarchy of biological organization from gene to functional cellular unit is generally accepted now, which includes the genome, the transcriptome, subproteomes and the proteome. In the case of skeletal muscle fibres, the motor neuron and all its inverted muscle fibres, usually termed motor unit, represent the functional biological basis of the excitationcontraction-relaxation cycle. In addition, skeletal muscle fibres are also major players in the maintenance of heat homeostasis and metabolic integration (17). Based on biochemical and physiological criteria, skeletal muscles can be divided into predominantly fast- or slow-twitching fibre populations. Since changes in neuromuscular activity or alterations in the mechanical loading conditions may severely affect skeletal muscle fibre composition (18-20), these biological factors have to be taken into account when one performs the comparative proteomic profiling of a diseased or aged muscle. The fact that muscle gene expression, protein levels and isoform patterns are closely related to innervation is illustrated by two important experimental findings. Firstly, the physical disconnection between a fibre unit and its respective motor neuron triggers rapid fibre atrophy (21) and secondly, artificial electro-stimulation causes pronounced changes in muscle activity (22). For example, the long-term dennervation of the mature rat extensor digitorum longus muscle triggers a $95 \%$ decrease in isometric contractile force and a two-third loss in muscle tissue mass within a month (23). This clearly illustrates the importance of judging muscle pathobiochemistry in the context of the essential nerve-muscle connection. Furthermore, studies on chronic electro-stimulation of fast muscle fibres, resistance training, endurance training, immobilization, and zero-gravity environments have shown that the nutritional supply and hormonal factors are also extremely important for skeletal muscle performance $(18-20,24,25)$. These factors have to be properly integrated into the overall biomolecular analysis of diseased muscle specimens, if one wants to properly understand the impact of changes caused by primary genetic mutations or acquired cellular abnormalities that impair the integrity of motor fibres.

Fig. 1 outlines the organizational hierarchy within a muscle, and the reference to the existence of a physiologically active motor unit takes into account that the adaptive response of skeletal muscle fibres depends, at least partially, on neuromuscular activity (18). One can therefore argue that 'the skeletal muscle proteome', as a distinct and unchangeable biological entity, does not exist. This is due to constant adaptive changes within the expression profile of all major groups of muscle proteins, thereby affecting the functional, structural and metabolic property of any given skeletal muscle under investigation. In addition, because of technical limitations in separating proteins of very different properties and expression levels, the biochemical isolation of the skeletal muscle proteome can only represent the near-to-total fibre proteome (26). In the case of the human genome, it is estimated that the approximate 30,000 identified genes

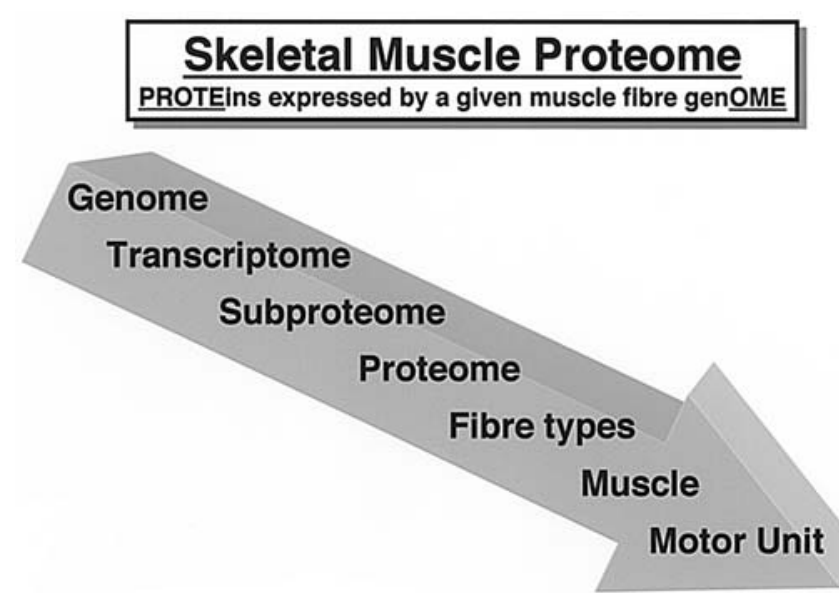

Figure 1. Diagrammatic presentation of the position of the skeletal muscle proteome within the organizational hierarchy of a motor unit. While the muscle genome stays relatively constant over a lifetime, the fibre proteome is in constant flux and undergoes pathobiochemical alterations or adapts to modified functional demands.

produce several 100,000 proteins, which is based on alternative splicing processes and post-translational modifications (27). Even the most advanced fluorescence difference gel electrophoretic approaches for studying entire skeletal muscle proteomes are not capable of presenting more than a few thousand individual protein species. It is estimated that the expression levels between proteins probably differ by several orders of magnitude, therefore no one biochemical separation technique is currently capable of resolving the entire muscle protein complement. However, despite these currently insurmountable biological and analytical difficulties, the combination of high-resolution 2-D gel electrophoresis with the application of novel fluorescence protein dyes can nevertheless give an excellent overview of major pathological changes in muscle diseases. In combination with protein analyses by high-throughput liquid chromatography (28) and comparison to data from transcriptomic studies, new disease markers can be readily identified at a drastically accelerated rate as compared to conventional biochemical approaches.

\section{Mass spectrometry-based proteomics}

The development of monoclonal antibodies as unique biochemical tools for the identification of proteins using immunochemical techniques, such as immunoblotting, has dominated biological research for over a decade (29). However, this relatively expensive screening approach with libraries of highly specific antibodies has more recently been replaced by MS-based identification methods (1-7). Although immunoblotting with suitable antibodies and direct peptide sequencing using automated procedures such as Edman degradation can be integrated into proteomic analyses, the most common analytical high-throughput technique is peptide mass fingerprinting (PMF). The development of MALDI-ToF and ESI-MS/MS methodology has put MSbased proteomics at the forefront for large-scale comparative studies $(8,9,30,31)$. The flowchart shown in Fig. 2 outlines a typical experimental set-up for the proteomic profiling of 


\title{
Proteomic Profiling of Skeletal Muscle
}

\begin{abstract}
Skeletal muscle proteomics is concerned with the global biochemical analysis of protein expression patterns in defined muscle fibres employing blological methods to separate and characterise proteins, as well as identify muscle proteins by interlinking with established protein sequence and two-dimensional gel electrophoretic databanks.
\end{abstract}

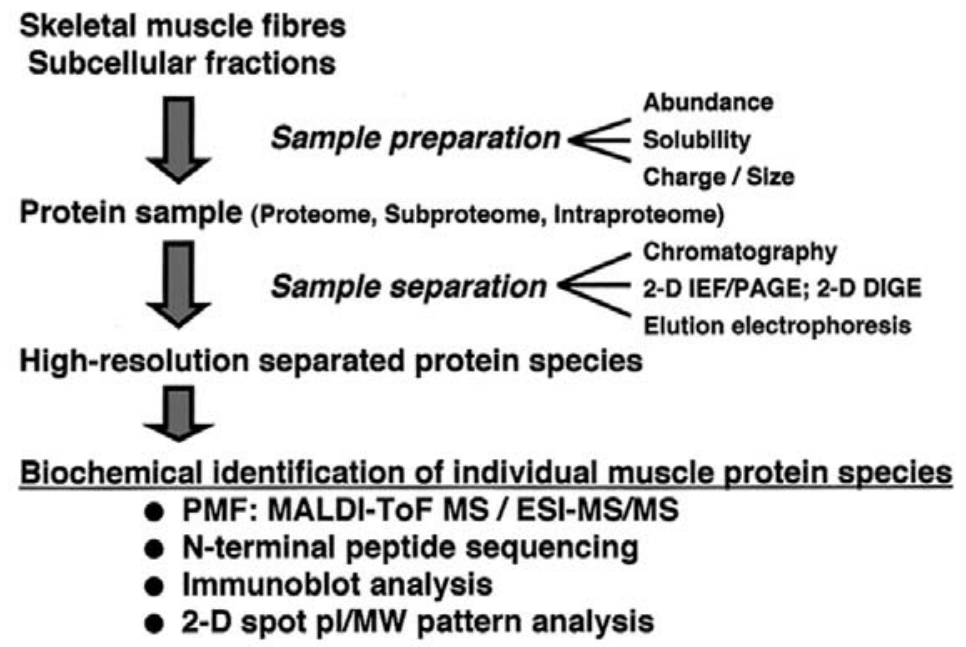

Figure 2. Flowchart of the proteomic profiling approach to study skeletal muscles. In order to study the entire accessible protein complement of a skeletal muscle, the protein fraction is extracted from crude fibre preparations or suitable subcellular fractions and then separated according to electrical charge and molecular mass. Individual protein species can be identified by peptide mass fingerprinting (PMF) using MALDI-ToF MS or ESI-MS/MS techniques. Alternatively, N-terminal peptide sequencing employing automated Edman degradation, immunoblotting surveys using libraries of monoclonal antibodies, or the comparison of the 2-D spot pattern with international databanks can be helpful in determining the identity of a novel biomarker protein

skeletal muscle specimens. Comparative proteomics is concerned with the qualitative and quantitative comparison of entire protein complements under varying biological conditions (7). Skeletal muscle proteomics in particular involves the global biochemical analysis of protein expression patterns in contractile fibres using standard techniques to separate and characterise muscle proteins, and then identify these protein species by interlinking with 2-D gel electrophoretic databanks and/or protein sequence databanks $(32,33)$. The skeletal muscle proteome is defined as the protein complement expressed by a given muscle fibre genome (26).

If the term 'proteome analysis' is used, one usually assumes that this involves total tissue extracts as starting material. The proteomic profiling of subcellular fractions is therefore referred to as subproteomics. In the case of muscle, the comparative proteomic screening of mitochondria, the sarcoplasmic reticulum or the sarcolemma falls therefore under this category. If the oligomeric status of proteins or robust heterogeneous protein-protein interactions is surveyed by proteomic technology, this analytical approach is usually called intraproteomics. As outlined in Fig. 2, individual muscle proteins within the entire proteome, the various subproteomes or the intraproteome differ greatly in their relative abundance, solubility, charge and size. These physical parameters are exploited in the biochemical separation of muscle proteins. Besides various chromatographical methods, the most common high-resolution separation of the skeletal muscle proteome is represented by 2-D gel electrophoresis. The application of isoelectric focusing in the first dimension and sodium dodecyl sulfate polyacrylamide gel electrophoresis in the second dimension is described below in detail. Once muscle proteins have been properly separated, PMF analysis is performed by MS in order to identify individual proteins $(9,30)$. Fig. 3 shows the identifying MS spectrum of the muscle component vimentin using PMF of in-gel digests. This technique relies on the assumption that the controlled digestion of a distinct protein species results in the generation of a unique set of peptides that exhibit a specific combination of molecular masses (31). The comparison of the determined molecular masses of a sub-set of trypsin-generated peptides with predicted values of vimentin fragments led to the identification of this intermediate filament protein, and its increased expression in muscular dystrophy $(34,35)$. The peptide population shown in the MS spectrum of Fig. 3 represents 11 matching sequences with a $26 \%$ coverage of the vimentin protein from Mus musculus. The MS data predict a pI-value of 5.09 and a relative molecular mass of $53.6 \mathrm{kDa}$ for the electrophoretically separated mouse muscle vimentin molecule. Thus, PMF can be employed for the identification of an unknown protein by performing a computational comparison of its trypsin-generated constituent fragment masses to the theoretical in silico generated peptide masses. Exhaustive trypsin treatment of a typical skeletal muscle protein usually results in peptides ranging from 500 to $2,500 \mathrm{kDa}$, as illustrated in Fig. 3. This method has initially been described by Henzel et al (36) and is now widely employed in the routine identification of proteins (37). Since the fingerprinting technique is a comparative method, an important prerequisite for the identification of a specific peptide mixture is the existence of a comprehensive and ideally species-specific protein- or DNA-based sequence databank for the biological material under investigation (33).

MALDI-ToF MS analysis of a protein sample involves the irradiation of a co-precipitate, consisting of the peptide or peptides of choice and a suitable UV-light absorbing matrix by a nano-second laser pulse $(30,31)$. For instrumental and 


\section{MALDI-ToF MS spectrum of vimentin-containing 2-D spot}

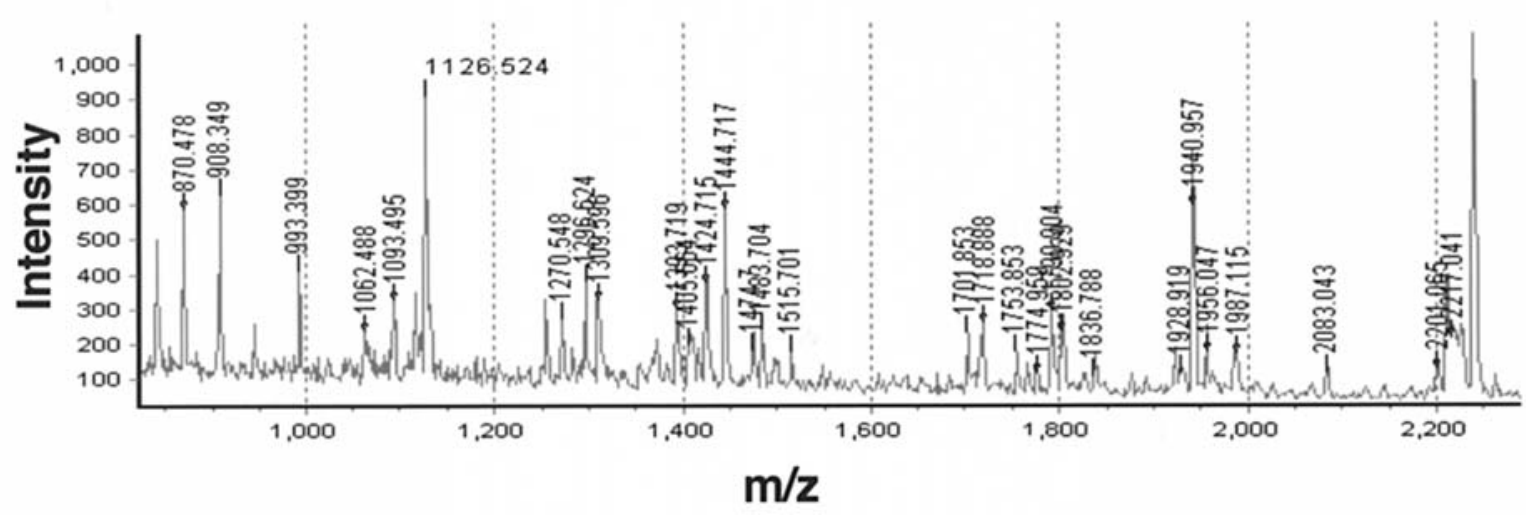

Figure 3. Identification of vimentin by peptide mass fingerprinting. Shown is the MALDI-ToF MS spectrum of a 2-D spot from mouse skeletal muscle following in-gel digestion. The scan exhibits the unique peptide population generated from the trypsination of the cytoskeletal protein vimentin with 11 matching sequences that account for a $26 \%$ coverage of the protein.

technical details, there are excellent books on the biological application of MS available (38-41). The underlying technical principle of a ToF mass spectrometer is that ions with a different mass/charge $(\mathrm{m} / \mathrm{z})$ ratio will traverse a constant electric field in a time that depends strictly upon their $\mathrm{m} / \mathrm{z}$ ratios. Thus, for a proper MALDI-ToF MS analysis, a group of biological ions must be subjected to the same electrical field and most of the laser energy has to be absorbed by the matrix, so that the biomolecules under investigation are not excessively fragmented. Following acceleration in the electric field, the ionized peptides enter a flight tube, where molecules separate according to their mass to charge ratio. This results in differential signals for individual ions when they reach the detector. The analytical measuring time is in the minute range and the sample amount needed for a distinct signal is in the pmol range, making MALDI-ToF MS technology an indispensable tool of modern protein biochemistry. As with any other biochemical technique, contaminants and various analytical variables may negatively affect the MS profiling. Problems can be due to the actual physico-chemical properties of the protein to be analysed, such as the predominant hydrophobic or hydrophilic properties of amino acid side chains. For a detailed description of MS methodology used in modern biochemistry, including the ESI-MS/MS technique for the direct determination of peptide sequences, please consult a recent review by Domon and Aebersold (9).

In the case of PMF, a very important parameter to be taken into account is the method of protein digestion. The publicly available search engine Mascot from Matrix Science (http://www.matrixscience.com) can handle 17 different enzymatic protocols. The most common method is trypsination of the protein of interest using sequencing-grade trypsin preparations. Subsequently, the proper mixing of generated peptides with a suitable matrix has to be accomplished, whereby the right concentration ratio and compatibility of matrix and peptide sample has to be taken into account. The choice of matrix for optimum MALDI results is therefore very important. Common matrices for protein work are $\alpha$-cyano-4-hydroxycinnamic acid, 3,5-dimethoxy-4-hydroxy- cinnamic acid and 2,5-dihydroxybenzoic acid (31). In addition, a low quantity of sample specimens will result in a weak detector signal that may lead to an insufficient analytical spectrum. The MS analysis of peptides generated from protein species that have originally been derived from crude protein mixtures might also be complicated by the presence of interfering chemicals. During solubilization procedures and the gel electrophoretic separation of muscle proteins for example, a high concentration of contaminants may associate with peptide fragments, such as Tris buffer molecules, urea, dithiothreitol or sodium dodecyl sulfate. If these contaminants interfere with a proper MS analysis, samples have to be precleaned to remove non-biomolecular components.

Besides MALDI-ToF technology, other high-throughput approaches for the swift identification of proteins are ESIMS/MS techniques, automated N-terminal sequencing or immunoblotting/dot-blotting with monoclonal antibodies. These well-established biochemical techniques are very reliable and routinely used in the initial screening procedure of proteins or employed in the confirmation of MALDI-ToF MS-generated lists of identified protein candidates. In addition, although not as reliable as direct peptide sequencing or ESI-MS/MS analysis, the simple comparison of the relatively unique combination of the isoelectric point and relative molecular mass of a particular 2-D protein spot with existing 2-D protein databanks can be employed to identify a protein (32). If the pI-value and the molecular mass of an unknown protein result in a positive hit in a tissue-specific databank, such as the SWISS-2DPAGE database (33), it is highly recommended that these findings be confirmed by immunoblotting. If no suitable antibodies to the skeletal muscle protein in question are available, automated $\mathrm{N}$-terminal peptide sequencing can be employed as an alternative method. Besides choosing the right identification tools in comparative proteomic studies, it is also crucial to keep in mind that the manipulation of tissue extracts may introduce artifacts. In skeletal muscle preparations, the presence of the highly abundant proteins myosin, actin, troponin and tropomyosin presents a serious problem during the 2-D separation 
of the fibre proteome. Pre-fractionation techniques have recently been developed that remove the major class of contractile muscle proteins prior to electrophoresis (42), but comparative proteomic approaches should avoid extensive fractionation schemes so that they can achieve a true representation of the skeletal muscle proteome from normal versus pathological specimens. Since any extraction procedures or subcellular fractionation steps may introduce, by their very nature, undesirable modifications in the composition of tissue preparations, it is recommended that crude skeletal muscle fibre preparations be used. This enables the best comparative way to investigate the entire accessible proteome of normal versus diseased muscles.

\section{Biomarker identification and comparative proteomics}

Comparative proteomics is a novel approach for determining qualitative and quantitative differences in the protein complement of a specific type of tissue under different biological or pathological conditions (1-7). Proteomics technology suggests itself for a comprehensive study of the muscle protein phenotype (26), since distinct alterations in the protein expression pattern of skeletal muscle fibres are involved in a variety of inherited neuromuscular disorders, acquired autoimmune diseases, pharmacogenetic afflictions, age-related complications, the biomedical design of cardiac assist pumps and physiological adaptations to changed functional demands (43). The search for new biomarkers of neuromuscular diseases and age-dependent fibre wasting in humans will be a difficult and complex task. In contrast to inbred animal strains used for disease model research, biopsy material from human patients is considerably more heterogeneous. Inter-individual differences between humans of the same age, gender and ethnical background are due to variations in life style, environmental exposure, nutrition, disease history and genetics. In addition, biopsy material taken at advanced stages of a muscle disease may not exhibit specific enough differences in the changed expression of disease markers, because many neuromuscular disorders may share common pathophysiological pathways during end-stage pathology (43).

In contrast to the human genome, the skeletal muscle proteome is constantly changing during a patient's lifetime, which constitutes another problem in the search for robust biomarkers. Clinically most human diseases have to be considered heterogeneous. For example sarcopenia, the agerelated decline in skeletal muscle strength and mass, is a heterogeneous muscle-wasting disorder with considerable variations in symptoms and severity (44-46). Different mutations in the same gene may trigger two different muscle pathologies, e.g. primary genetic abnormalities in the ryanodine receptor $\mathrm{Ca}^{2+}$-release channel of the sarcoplasmic reticulum may cause central core disease or convey susceptibility to the pharmacogenetic disorder malignant hyperthermia $(47,48)$. On the other hand, mutations in two different genes may result in a very similar disease process with comparable symptoms, e.g. certain mutations in the dihydropyridine receptor or the ryanodine receptor may be both associated with malignant hyperthermia $(48,49)$. Thus, many technical and biological obstacles have to be overcome and certain minimum criteria established before one can properly integrate

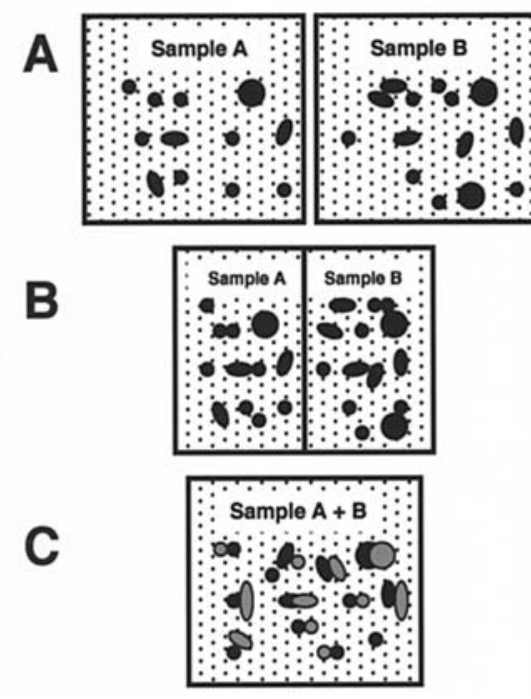

\section{Comparative 2D-IEF/PAGE \\ Comparative 2D-IEF/ 2-in-1 PAGE}

\section{Fluorescence DIGE Difference in-gel electrophoresis}

Figure 4. Diagrammatic comparison between 3 types of gel electrophoretic methods used in skeletal muscle proteomics. Traditionally, as shown in panel A, different proteomes are displayed on different 2-D gels and then compared by densitometric analysis. Alternatively, to avoid statistical errors due to unavoidable gel-to-gel variations, both first dimension gels can be separated in parallel on the same 2-D slab gel (B). Panel C outlines the most advanced comparative proteomic approach using differential fluorescent tagging of proteomes prior to their separation on the same 2-D gel. Difference in-gel electrophoresis (DIGE) is one of the most sensitive detection techniques available for comparative biochemical studies in the search for novel biomarkers of neuromuscular diseases.

a new biomarker into the existing diagnostic scheme of muscle pathology. A robust and reliable biomarker should be: i) soluble for ease of access, ii) relatively abundant so that unfavorable signal-to-noise ratios do not become a problem, iii) not greatly different in density between individual control samples so that its statistical evaluation does not represent a complex problem, iv) of consistent concentration in non-disease samples over time, and v) highly disease-specific so that the existence of common pathophysiological pathways does not lead to a misdiagnosis. 2-D gel electrophoresis in combination with high-throughput protein identification via PMF can be conveniently used for studying changes in the skeletal muscle proteome. Therefore, another important biochemical criteria for a good biomarker is that the protein must be sensitive to common proteolytic procedures, such as trypsination, for its proper initial identification. Besides cataloging skeletal muscle proteins, recent applications of muscle proteomics have led to the identification of changes in the skeletal muscle proteome during aging, muscular dystrophy, and fibre transformation, as described below in detail. Thus, the worldwide effort to find new disease markers should soon translate into improved diagnostic procedures and the identification of novel therapeutic targets for the future treatment of muscle diseases.

Standard comparative proteomics usually uses two separate gels, which represent a control specimen and a diseased or conditioned sample for subsequent densitometric analysis (3). As illustrated in Fig. 4, besides using two separate gels, samples can also be analysed in parallel or as a pre-labeled mixture on one 2-D slab gel. The more advanced 
difference gel electrophoresis approach, now commonly referred to as DIGE, exploits the differential fluorescence labeling of more than one protein complement, which are then separated on the same gel system (50-53). This technique considerably reduces gel-to-gel variation, but is also extremely costly with respect to fluorescence tagging and licensing of the analysis software package (50). The DIGE method is based on the use of multiple fluorescent dyes for labeling protein samples prior to their electrophoretic separation (50-53). The three most commonly used Cy dyes are $\mathrm{Cy} 2, \mathrm{Cy} 3$ and $\mathrm{Cy} 5$, which are excited with lasers at 488, 532 and $635 \mathrm{~nm}$, respectively. Usually, the control or normal sample is labeled with $\mathrm{Cy} 3$ and the disease or treated sample is labeled with Cy5. A pooled mixture of both samples is then labeled with the Cy2 dye and serves as an internal standard. All three differentially labeled protein suspensions are then separated on the same 2-D gel and a multiplexed image is analysed by comparing any specific protein spot to its own internal standard. As illustrative examples, the differential fluorescence DIGE gel staining pattern of unstimulated versus chronic low-frequency stimulated tibialis anterior muscle (Fig. 5A) and of normal versus dystrophic diaphragm fibres (Fig. 5B-G) is shown. Although usually the Cy2 dye is used for the labeling of the pooled standard, any combination of the $\mathrm{Cy} 2, \mathrm{Cy} 3$ and $\mathrm{Cy} 5$ dyes can be employed in comparative DIGE studies. In Fig. 5A, the Cy2-labeled 50:50 mixture of both muscle type proteomes has been used as an internal standard, while in Fig. 5D and G the Cy5-pooled fraction has been employed for standardization of expression levels. Both analyses are discussed in detail in subsequent sections on muscular dystrophy and muscle plasticity.

The analysis of fluorescence labeling patterns by 2-D DIGE software programmes results in a list of the ratio of relative protein expression. Compared to conventional protein dyes, such as Coomassie or silver, which usually visualize not more than a few hundred protein species, the fluorescent DIGE method is capable of recognizing thousands of muscle proteins in large 2-D-gel systems. Using multi-gel electrophoresis apparatuses that can accommodate 6 to 12 individual DIGE gels for a parallel run, all necessary data points can be generated in one swift analytical procedure. Once all the different preparative steps have been optimized, the comparative densitometric analysis of protein expression in a normal versus disease proteome can be accomplished within a week. The protein identity of 2-D spots with a drastically changed density can then be determined by PMF using MALDI-ToF MS or ESI-MS/MS. To confirm the identity of a specific protein and to further characterise the extent of expression changes, immunoblotting can be employed.

Although the fluorescent DIGE technique is extremely sensitive and widely applicable to comparative proteomics (50-53), it is also very expensive with respect to both running costs and the need for specialized equipment. Here, we outline an alternative procedure for a cost-effective comparative proteomic analysis, which also reduces gel-to-gel variation by using the same 2-D slab gel for the analysis of two separate specimens, but without the need for differential fluorescence labeling. This simplified method can be used to initially optimize the sample preparation for comparative proteomics

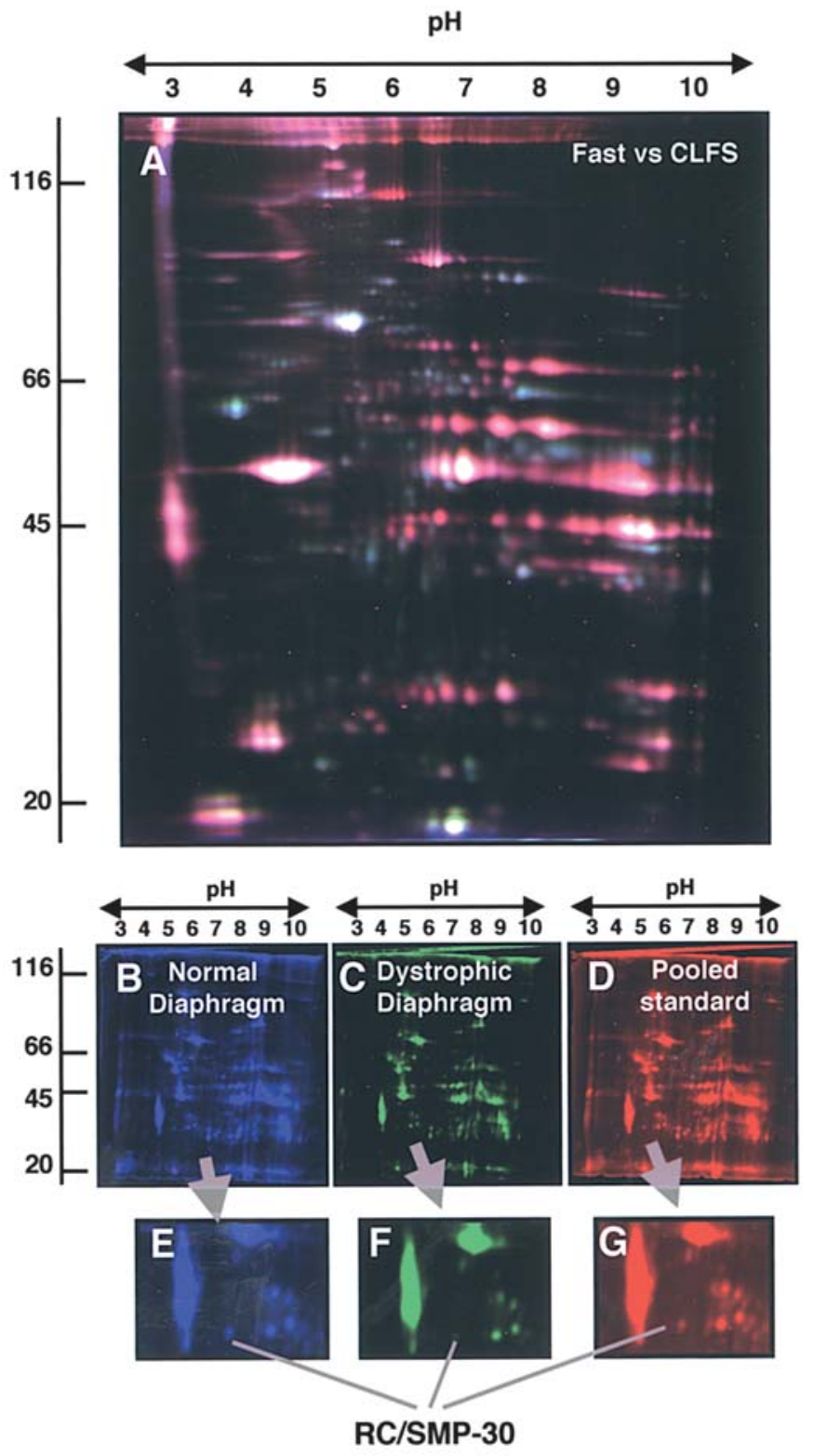

Figure 5. Fluorescence difference in-gel electrophoretic analysis of transformed tibialis anterior muscle and dystrophic diaphragm muscle. Shown is the differential fluorescent 2-D separation pattern of the fasttwitch versus the transformed slow-twitch muscle proteome. The rabbit tibialis anterior muscle has been chronic low-frequency stimulated (CLFS) and then tagged with the fluor dye Cy5 or not electro-stimulated and then tagged with the fluor dye Cy3. For internal standardization, the protein complement from both specimens were mixed and labeled with the fluor dye Cy2. Panels B-D illustrate representative 2-D gels of normal diaphragm, dystrophic diaphragm and a mixed internal standard which have been labeled with the fluorescent dyes $\mathrm{Cy} 2, \mathrm{Cy} 3$ and $\mathrm{Cy} 5$, respectively. The $\mathrm{pH}-$ values of the first dimension gel system and molecular mass standards (in $\mathrm{kDa}$ ) of the second dimension are indicated on the top and on the left of the panels, respectively. Panels E-G show enlargements of the three fluorescent images of the fluor Cy dyes, clearly demonstrating a drastic reduction of the cytosolic $\mathrm{Ca}^{2+}$-binding protein regucalcin in dystrophin-deficient muscle fibres. Regucalcin (RC) is also referred to as senescence marker protein of $30 \mathrm{kDa}$ (SMP-30). DIGE gels of the skeletal muscle proteome can separate several thousand individual protein species making it the preferred method for the initial discovery of new biomarkers

prior to a more comprehensive DIGE analysis, or be employed as an inexpensive alternative for a swift search of novel biomarkers of diseases. The 2-in-1 2-D gel electrophoretic 


\section{Comparative 2D-GE}
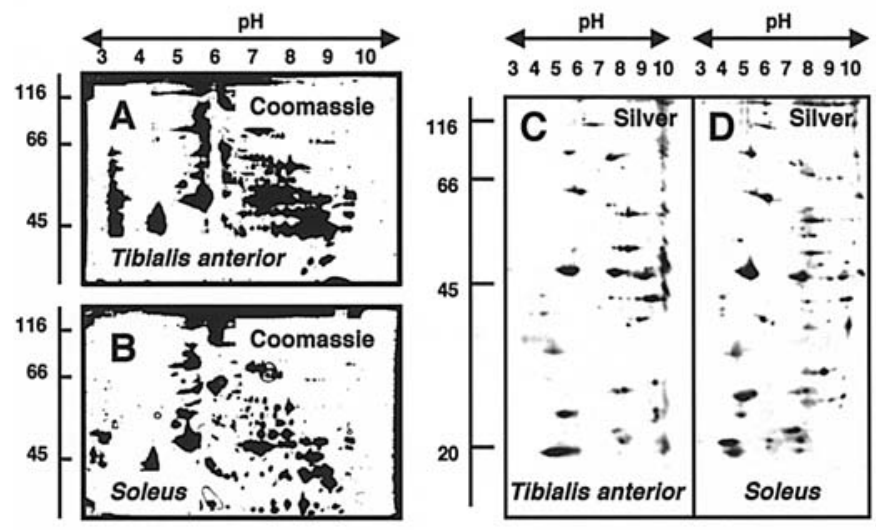

Figure 6. Comparison of the 2-D separation pattern of the fast-twitch versus the slow-twitch muscle proteome. Shown are separate Coomassie-stained 2$\mathrm{D}$ gels of the rabbit tibialis anterior (A) and soleus (B) muscle proteome. As outlined in the diagram of Fig. 4, in order to avoid extensive gel-to-gel variations, both first dimension gels can be run on the same 2-D slab gel, as shown in the silver-stained gels of fast and slow fibres in panels (C) and (D). The pH-values of the first dimension gel systems and molecular mass standards (in $\mathrm{kDa}$ ) of the second dimension gels are indicated on the top and on the left of the panels, respectively.

method has recently been successfully applied to the proteomic analysis of chronic low-frequency-stimulated muscle fibres (54), as discussed in detail below. Since skeletal muscle is a relatively tough tissue for preparing cell extracts and because muscle fibres contain many problematic protein species with respect to an efficient 2-D gel electrophoretic separation, muscle proteomics is accompanied by an array of technical problems. However, the proper optimization of the initial sample preparation step can at least partially overcome these difficulties. Studies over the last few years have clearly demonstrated that 2-D gel electrophoresis and MS-based proteomics can be used for the comparative screening of highly complex mammalian tissues. To illustrate this point, we show here the findings of a comparative electrophoresis analysis of total tissue extracts from slow and fast muscle fibres on one 2-D slab gel. Fig. 6 shows that this technique is capable of detecting distinct differences in varying protein phenotypes. The conventional comparison using two separate 2-D gels and Coomassie-staining is illustrated in Fig. 6A and B, and contrasted to the alternative method employing comparative 2-in-1 2-D gel electrophoresis with silver- staining (Fig. 6C and D). The protein spot pattern exhibits distinct differences between tibialis anterior and soleus preparations. The protein expression profiling of different fibre types shown here agrees with the physiological and biochemical specialisation of muscles with unique contractile capabilities (18-20). How the alternative 2-in-1 gel electro-phoresis method can be integrated into a comparative proteomic approach, and be used as a simplified and cost-effective first step in the characterisation of a pathological specimen, is outlined in the flow chart of Fig. 7.

\section{Skeletal muscle proteomics}

Skeletal muscle proteomics represents a new analytical tool for the cataloging of extractable protein components and the determination of fibre-specific expression patterns (26). In contrast to soluble biological materials and soft tissues, skeletal muscle fibres represent an extremely tough tissue consisting of gigantic cellular structures. A healthy skeletal muscle fibre is a long, cylindrical and multi-nucleated cellular unit, which is usually 10 to $100 \mu \mathrm{m}$ in diameter and may vary in length from millimeters to centimeters (17). Approximately fifty percent of a muscle fibre's protein content is made up of the contractile machinery, mostly consisting of myosin complexes of the thick filaments and actin strings of the thin filaments, as well as the regulatory elements tropomyosin and the troponin complex. The

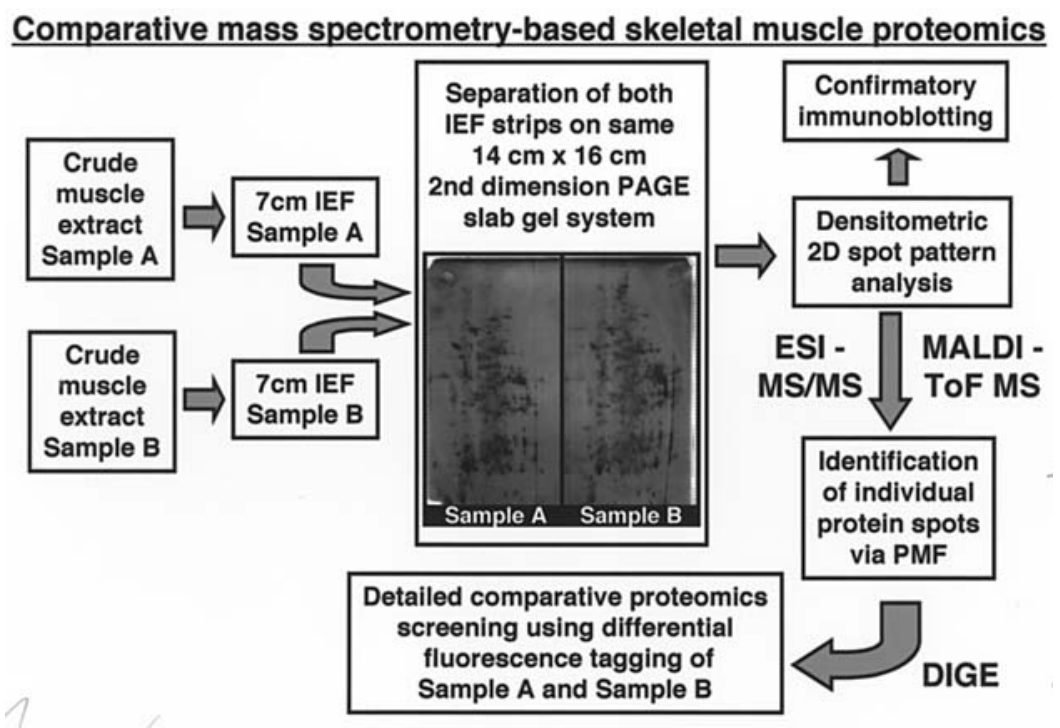

Figure 7. Flowchart of comparative proteomic profiling of skeletal muscle. For a cost- and time-effective initial analysis of two different muscle proteomes, fibre extracts can be first studied by a 2-in-1 slab gel approach, as diagrammatically shown in Fig. 4 . Interesting candidate 2-D spots with a drastically changed expression level can then be analysed by MALDI-ToF MS and/or ESI-MS/MS techniques. Based on these findings, a more detailed comparative proteomics screening can be performed using the fluorescence DIGE method, as shown in the 2-D gels in Fig. 5. 
extremely high density of four protein species within one class of tissue causes certain technical problems with the 2-D gel electrophoretic separation of crude muscle extracts. Although the main contractile muscle proteins exist in a variety of isoforms (55), due to their similar molecular mass and isoelectric point they form protein spot cluster within similar areas in a standard 2-D slab gel. Thus, in order to avoid cross-contamination and sample streaking during electrophoretic separation, the total amount of protein loading is more limited in muscle proteomics as compared to other tissues. In addition, skeletal muscle fibres consist of highly abundant and complex internal membrane systems and organelles that contain a considerable amount of relatively insoluble protein. The presence of contractile proteins and integral receptor clusters therefore complicates the proper separation of crude muscle extracts in 2-D gels. Hence, the proteomic evaluation of complex mammalian tissues, such as skeletal muscles, usually necessitates an initial optimization procedure to solubilize the maximum amount of individual classes of proteins.

Although it is possible to load a considerably higher concentration of muscle protein per first dimension gel, the optimum amount of fibre protein per isoelectric focusing strip is approximately 50 to $200 \mu \mathrm{g}$ for a comparative proteomic approach $(34,35,54,56)$. Low protein concentrations $(<50 \mu \mathrm{g}$ total protein) cause minimal cross-contamination between individual 2-D spots, but the resulting staining pattern is usually too weak for proper spot picking when conventional non-fluorescent protein dyes are used. Loading with several $100 \mu \mathrm{g}$ of protein has the opposite effect and results in the appearance of many hundred distinct silver-stained muscle protein spots. However, a very high protein concentration also results in undesirable protein streaking in both gel dimensions. Electrophoretic artifacts are caused by charged trains of proteins in the first dimension and spot smearing due to abnormal mobility shifts of high-density muscle proteins in the second dimension. Even if these experimental considerations are taken into account during pilot studies, a good 2-D separation of muscle components is limited to proteins of certain size and charge. For fluorescence DIGE analysis, the recommended total protein concentration of all 3 labeled protein complements is $150 \mu \mathrm{g}$ (50-53), which is suitable for comparative skeletal muscle proteomics (35).

Using standard 2-D gel procedures, very acidic muscle proteins usually do not properly separate and form vertical streaking at the $\mathrm{pH} 3.0$ region. A high degree of heterogeneous glycosylation of the same protein backbone or the presence of extensive hydrophobic peptide domains may trigger considerable smearing of spot patterns. Since many muscle surface proteins are highly glycosylated, the proteomic profiling of the sarcolemma and transverse tubular membrane systems can be complicated by the distortion of protein spots. Integral membrane proteins with extensive hydrophobic characteristics often cannot be sufficiently solubilized and are therefore underrepresented in standard 2-D gels. Another problem is presented by the proteomic profiling of very highmolecular-mass proteins, since they do not enter the second dimension in sufficient amounts for reproducible examinations. For example, large proteins such as the $\alpha_{1 \mathrm{~S}}$-dihydropyridine receptor of $175 \mathrm{kDa}(57)$ and the myosin heavy chain of $220 \mathrm{kDa}$
$(35,56)$ move into the second dimension after isoelectric focusing, but very large proteins such as dystrophin of $427 \mathrm{kDa}$ or the ryanodine receptor $\mathrm{Ca}^{2+}$-release channel of $565 \mathrm{kDa}$ do not properly transfer from the first to the second slab gel dimension. Thus, studies on the primary defective protein in Duchenne muscular dystrophy (58) or the major mutant factor involved in susceptibility to the pharmacogenetic disorder malignant hyperthermia (49) cannot be executed using conventional 2-D gel electrophoresis. However, alternative diagonal 2-D gel techniques can be employed to study extremely high-molecular-mass proteins, such as triadin aggregates (59). These kinds of 2-D gels employ combinations of native versus reducing conditions, or nonreducing versus reducing dimensions, and can thus be used to characterise protein oligomerisation (57).

Skeletal muscles represent the most abundant type of mammalian tissue and display an enormous adaptive and plastic potential. One of the most striking physiological and biochemical characteristics of adult muscle fibers is their intrinsic ability to adjust their structural, metabolic and functional properties (19). Although fully differentiated and functionally integrated within motor units, a mature muscle can undergo extensive fibre type shifting in response to changed physiological or pathophysiological demands (20). In order to further our understanding of the molecular mechanisms that underlie these biological adaptations and modulations of muscle tissues during myogenesis, differentiation, fibre aging and neuromuscular disease progression, the improvement of reliable and swift methods for the identification of muscle markers is essential. The introduction of comparative transcriptomics and proteomics has decisively enhanced the technical capabilities of myologists to find novel muscle components that are involved in biological and pathological processes. Since skeletal muscles are not only involved in contraction, but also heat homeostasis and metabolic integration, muscle proteomics is important for understanding whole-body physiology. On the molecular level, the array of biomolecules involved in elasticity, extensibility, excitability and contractility of the muscular system have not been fully elucidated (17). Possibly a more comprehensive cataloging of muscle proteins via proteomic profiling may identify novel protein factors involved in the maintenance and regulation of skeletal muscle function. With the help of sophisticated 2-D software analysis and statistics programmes, it is now possible to perform proteomic investigations of animal disease models with relatively limited amounts of individual specimens. In stark contrast, clinical proteomic studies must take into account inter-individual differences between patients and therefore need higher experimental repeats.

Table I lists recent key studies that have used proteomics to study skeletal muscle biology, showing how useful this new systematic approach is for the identification of fibre protein isoforms. Comprehensive 2-D reference maps of the skeletal muscle proteome have been established for mouse (33), rat $(60)$, bovine $(61,62)$ and human $(63-65)$ tissues. Since fibre type shifting plays an important role in various neuromuscular disorders and is also an important physiological mechanism during normal adaptations to changed functional demands, the cataloging of fast- and slow-twitch biomarkers 
Table I. Major skeletal muscle studies that have employed proteomic profiling.

\begin{tabular}{|c|c|c|c|}
\hline Proteomic profiling & Major finding & Tissue/species & Reference \\
\hline \multirow[t]{8}{*}{ Protein cataloging } & $\begin{array}{l}\text { Establishment of SWISS-2DPAGE } \\
\text { database }\end{array}$ & Normal mouse skeletal muscle & Sanchez et al (2001) (33) \\
\hline & $\begin{array}{l}\text { Comprehensive 2-D reference map of } \\
\text { muscle proteome }\end{array}$ & Normal rat skeletal muscle & Yan et al (2001) (60) \\
\hline & $\begin{array}{l}\text { Summary of identified muscle proteins } \\
\text { using proteomics }\end{array}$ & Various & Isfort (2002) (26) \\
\hline & 2-D reference map of muscle proteome & $\begin{array}{l}\text { Normal human vastus lateralis } \\
\text { muscle }\end{array}$ & Gelfi et al (2003) (63) \\
\hline & 2-D reference map of muscle proteome & $\begin{array}{l}\text { Normal human deltoideus } \\
\text { versus vastus lateralis }\end{array}$ & Capitanio et al (2005) (64) \\
\hline & 2-D reference map of muscle proteome & Normal human laryngeal muscle & Li et al (2003) (65) \\
\hline & $\begin{array}{l}\text { Comprehensive 2-D reference map of } \\
\text { muscle proteome }\end{array}$ & $\begin{array}{l}\text { Normal bovine semitendinosus } \\
\text { muscle }\end{array}$ & Bouley et al (2004) (61) \\
\hline & $\begin{array}{l}\text { 2-D reference map of alkaline proteins } \\
\text { in bovine muscle }\end{array}$ & Normal bovine muscle & Chaze et al (2006) (62) \\
\hline $\begin{array}{l}\text { Mitochondrial } \\
\text { subproteome }\end{array}$ & $\begin{array}{l}\text { Proteomic comparison of mitochondrial } \\
\text { protein complement in muscle and heart }\end{array}$ & Normal rat muscle versus heart & Forner et al (2006) (70) \\
\hline Muscle glycoproteome & $\begin{array}{l}\text { Identification of O-linked and } \\
\mathrm{N} \text {-acetylglucosamine proteins in muscle }\end{array}$ & Normal rat muscle & $\begin{array}{l}\text { Cieniewski-Bernard et al } \\
\text { (2004) (71) }\end{array}$ \\
\hline \multirow[t]{2}{*}{ Fibre type cataloging } & $\begin{array}{l}\text { Fibre type specific differences in protein } \\
\text { expression between red and white pork } \\
\text { meat }\end{array}$ & $\begin{array}{l}\text { Normal porcine longissimus } \\
\text { dorsi versus soleus muscle }\end{array}$ & Kim et al (2004) (66) \\
\hline & $\begin{array}{l}\text { Fibre type specific differences in protein } \\
\text { expression between predominantly fast- } \\
\text { and slow-twitching mouse muscles }\end{array}$ & $\begin{array}{l}\text { Normal and kyphoscoliotic } \\
\text { muscle }\end{array}$ & $\begin{array}{l}\text { Le Bihan et al (2004) (28); } \\
(2006)(67)\end{array}$ \\
\hline
\end{tabular}

Normal rat extensor digitorum longus versus soleus muscle

Normal rat gastrocnemius versus soleus muscle

Chronic low-frequencystimulated rabbit tibialis anterior

Normal chicken pectoralis muscle

Determination of muscle protein dynamics under conditions of rapid growth

Myoblast differentiation Profile of the biochemical adaptations associated with skeletal muscle development

Muscle exercise

Skeletal muscle hypertrophy

Immobilization-induced muscular atrophy

Muscular dystrophy
Identification of exercise-induced changes in the skeletal muscle proteome

Determination of the effect of myostatin deficiency on the fast muscle phenotype

Profile of global protein changes during muscular atrophy following hindlimb suspension

Decrease in adenylate kinase in dystrophin-deficient fibres

\section{Mouse-derived C2C12} myoblasts

Mouse gastrocnemius muscle following swim exercise

Heterozygote and homozygote Belgian blue bulls semitendinosus muscle

Immobilized rat soleus and tibialis anterior muscle

MDX mouse hindlimb muscle
Okumura et al (2006) (68)

Gelfi et al (2006) (69)

Donoghue et al (2005) (54)

Doherty et al (2004) (72)

Kislinger et al (2005) (73)

Takahashi and Kubota (2005) (74)

Bouley et al (2005) (75)

Isfort et al $2002(79,80)$

Ge et al (2003) (81) 
Table I. Continued.

\begin{tabular}{|c|c|c|c|}
\hline Proteomic profiling & Major finding & Tissue/species & Reference \\
\hline \multirow[t]{4}{*}{ Muscular dystrophy } & $\begin{array}{l}\text { Determination of disturbed protein } \\
\text { expression pattern in dystrophic } \\
\text { mice at different ages }\end{array}$ & $\begin{array}{l}\text { Cytosolic fraction of MDX } \\
\text { mouse muscle }\end{array}$ & Ge et al (2004) (82) \\
\hline & $\begin{array}{l}\text { Decreased expression of the luminal } \\
\text { calcium-binding protein calsequestrin } \\
\text { in dystrophin-deficient fibres }\end{array}$ & $\begin{array}{l}\text { Mildly dystrophic MDX mouse } \\
\text { hindlimb muscle }\end{array}$ & Doran et al (2004) (56) \\
\hline & $\begin{array}{l}\text { Decreased expression of the cytosolic } \\
\text { calcium-binding protein regucalcin } \\
\text { in dystrophin-deficient fibres }\end{array}$ & $\begin{array}{l}\text { Severely dystrophic MDX } \\
\text { mouse diaphragm }\end{array}$ & Doran et al (2006) (34) \\
\hline & $\begin{array}{l}\text { Drastic increase in the stress protein } \\
\text { cvHSP in dystrophin-deficient fibres }\end{array}$ & $\begin{array}{l}\text { Severely dystrophic MDX } \\
\text { mouse diaphragm }\end{array}$ & Doran et al (2006) (35) \\
\hline Dysferlinopathy & $\begin{array}{l}\text { Profile of differentially expressed muscle } \\
\text { proteins in dysferlin-deficient fibres }\end{array}$ & $\begin{array}{l}\text { Normal versus dysferlin- } \\
\text { deficient human muscle }\end{array}$ & De Palma et al (2006) (83) \\
\hline $\begin{array}{l}\text { Mitochondrial muscle } \\
\text { disease }\end{array}$ & $\begin{array}{l}\text { Concept of identifying novel protein } \\
\text { factors involved in neuromuscular } \\
\text { diseases }\end{array}$ & Pathological human muscle & $\begin{array}{l}\text { Van de Heuvel et al } \\
\text { (2003) (15) }\end{array}$ \\
\hline \multirow[t]{5}{*}{ Muscle aging } & $\begin{array}{l}\text { 2-D reference map of effects of } \\
\text { sarcopenia of old age }\end{array}$ & $\begin{array}{l}\text { Young versus old human } \\
\text { muscle }\end{array}$ & Cobon et al (2002) (16) \\
\hline & $\begin{array}{l}\text { Identification of age-dependent protein } \\
\text { nitration in skeletal muscle }\end{array}$ & Young versus old rat muscle & $\begin{array}{l}\text { Kanski et al (2003) (84); } \\
(2005)(85)\end{array}$ \\
\hline & $\begin{array}{l}\text { Optimisation of 2-D gel system for } \\
\text { studying the effect of aging on } \\
\text { mitochondrial protein expression }\end{array}$ & $\begin{array}{l}\text { 18-month-old mouse hindlimb } \\
\text { muscle }\end{array}$ & Chang et al (2003) (86) \\
\hline & $\begin{array}{l}\text { Identification of changes in the skeletal } \\
\text { muscle proteome during aging }\end{array}$ & $\begin{array}{l}\text { 7-month versus } 30 \text {-month-old } \\
\text { rat gastrocnemius muscle }\end{array}$ & Piec et al (2005) (87) \\
\hline & $\begin{array}{l}\text { Determination of age-dependent changes } \\
\text { in the human skeletal muscle proteome }\end{array}$ & $\begin{array}{l}\text { Young verus old human } \\
\text { vastus muscle }\end{array}$ & Gelfi et al (2006) (88) \\
\hline $\begin{array}{l}\text { Effect of frozen storage } \\
\text { on protein pattern }\end{array}$ & $\begin{array}{l}\text { Differential analysis of cod muscle } \\
\text { stored under various conditions }\end{array}$ & Normal cod muscle & Kjaergard et al (2006) (76) \\
\hline $\begin{array}{l}\text { Effect of dietary } \\
\text { manipulations }\end{array}$ & $\begin{array}{l}\text { Profile of protein expression patterns in } \\
\text { rainbow trout following different diets }\end{array}$ & Normal rainbow trout muscle & Martin et al (2003) (77) \\
\hline $\begin{array}{l}\text { Neuromuscular } \\
\text { synapse formation }\end{array}$ & $\begin{array}{l}\text { Identification of secreted muscle } \\
\text { components involved in neuromuscular } \\
\text { junction formation }\end{array}$ & $\begin{array}{l}\text { Mouse soleus muscle and } \\
\text { Sol8 myotubes }\end{array}$ & Gajendran et al (2002) (78) \\
\hline
\end{tabular}

is an extremely important topic of modern muscle biology. Fibre type cataloging has been performed for skeletal muscles from various species, including the pig (66), mouse $(28,67)$ rabbit $(54)$ and rat $(68,69)$. Over the last few years, many fundamental physiological, biochemical and cellular processes associated with skeletal muscle fibres have been studied by proteomics, such as the mitochondrial subproteome (70), the muscle glycoproteome (71), muscle growth (72), myoblast differentiation (73), exercise-induced changes in the muscle proteome (74), muscle hypertrophy (75), the effect of freezing conditions on meat storage (76), the effect of dietary manipulations (77) and neuromuscular synapse formation (78). Another important area of comparative muscle proteomics is the study of diseased human tissue and animal models. The focus has been on immobilization- induced muscular atrophy $(79,80)$, muscular dystrophy $(34,35,56,81,82)$, dysferlinopathy $(83)$, mitochondrial muscle disease (15) and sarcopenia (16,84-88).

For comparative studies it is extremely useful to employ landmark 2-D spots to check equal loading conditions and the reproducibility of gel electrophoretic separation techniques $(26,33,60,63)$. In our experience, key contractile and regulatory proteins and certain metabolic marker enzymes represent a sufficient number of easily recognisable spots to quickly evaluate a 2 -D-separated skeletal muscle proteome $(34,35,54,56)$. Useful muscle protein landmark spots include the following relative unique combinations of the isoelectric point and apparent molecular mass $(35,56)$ : pI5.8/70 kDa (albumin), pI7.8/47 kDa (enolase), pI8.6/40 kDa (aldolase), pI9.1/29 kDa (phosphoglycerate mutase), pI7.1/27 kDa 


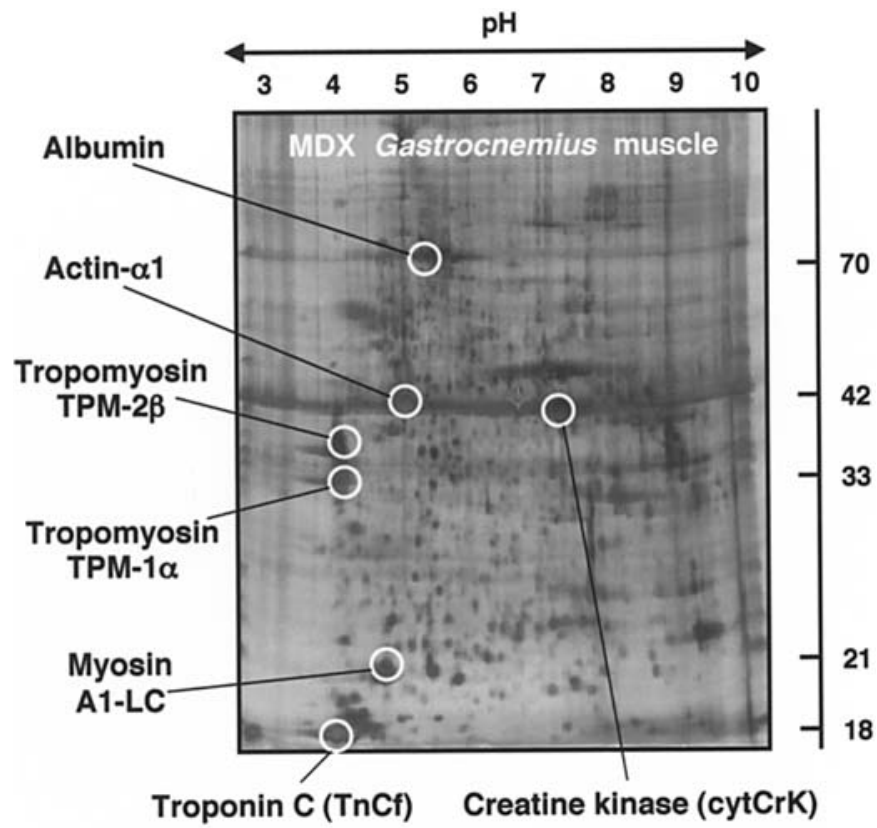

Figure 8. Illustration of 2-D landmark gel spots from crude skeletal muscle extracts. In order to judge the proper extraction and gel electrophoretic separation of muscle proteins, the position and relative size of abundant 2-D landmark spots is extremely useful. Shown is a silver-stained 2-D gel of the total gastrocnemius muscle extract from the dystrophic mouse model MDX. The position of easily detectable isoforms of albumin, actin, tropomyosin, troponin, myosin and the cytosolic creatine kinase is indicated. The $\mathrm{pH}$ values of the first dimension gel system and molecular mass standards (in $\mathrm{kDa}$ ) of the second dimension are indicated on the top and on the left of the panels, respectively.

(triosephosphate isomerase), pI4.7/33 kDa (tropomyosin 2), pI6.1/30 kDa (slow troponin T), pI6.7/31 kDa (fast troponin T), pI4.8/18.9 kDa (slow myosin light chain 2), pI4.8/19 kDa (fast myosin light chain 2), pI5.0/21 kDa (fast myosin light chain 1), pI5.2/42 kDa (actin), pI6.6/43 kDa (mitochondrial creatine kinase), pI6.6/43 kDa (cytosolic creatine kinase), pI9.1/22 kDa (adenylate kinase), pI6.8/20 kDa (crystallin) and pI6.7/17 kDa (myoglobin). Fig. 8 shows a representative 2-D reference gel of the MDX gastrocnemius muscle, outlining landmark spots of albumin, actin- $\alpha 1$, myosin light chain A1-LC, tropomyosin TPM-1 $\alpha$, tropomyosin TPM-2ß, fast troponin $\mathrm{C}$, and the cytosolic creatine kinase $(34,54)$.

\section{Comparative proteomic analysis of muscular dystrophy}

Muscular dystrophies are a group of progressive fibre-wasting diseases with distinct mutations or rearrangements in genes encoding essential structural or functional muscle proteins (89). One of the most severe forms is represented by Duchenne muscular dystrophy, which is the most frequent neuromuscular disorder in humans (90). A primary deficiency in the Dp427 isoform of the membrane cytoskeletal protein dystrophin is the underlying genetic cause of muscle degeneration in Duchenne patients. The loss of dystrophin causes a severe reduction in a subset of sarcolemmal proteins, including sarcoglycans, sarcospan, dystroglycans, syntrophins and dystrobrevins $(58,91)$. In addition, dystrophin-associated signaling elements, such as the neuronal isoform of the enzyme nitric oxide synthase, are also affected in X-linked muscular dystrophy (92). The dystrophin-glycoprotein complex stabilizes the cellular periphery in healthy muscle fibres by linking the extracellular matrix element laminin to the actin membrane cytoskeleton (93). The absence of fulllength dystrophin and the reduction in dystrophin-associated surface proteins impairs the integrity of the muscle plasmalemma by disturbing the trans-sarcolemmal connection. A weakened structural support of the dystrophic sarcolemma was shown to cause an increased frequency of membrane micro-rupturing. Injured muscle fibres usually reseal very quickly in a $\mathrm{Ca}^{2+}$-dependent process. In muscular dystrophy, this natural membrane repair mechanism appears to introduce a class of not well-characterised $\mathrm{Ca}^{2+}$-leak channels into the dystrophic plasmalemma triggering a pathophysiological increase of the cytosolic $\mathrm{Ca}^{2+}$-concentration (94). Elevated $\mathrm{Ca}^{2+}$-levels are implicated in rendering fibres more susceptible to tissue degradation via activation of proteolytic pathways (95). Since most pathological processes exhibit a molecular hierarchy with respect to aberrant signaling patterns and abnormal downstream events, it is believed that the deficiency in dystrophin and the loss of dystrophin-associated glycoproteins also initiates a stepwise insult to the muscular system, eventually leading to impairment of ion homeostasis, abnormal excitation-contraction coupling and disturbed energy metabolism in dystrophinopathies $(96,97)$.

An inherited one-gene disease, such as Duchenne muscular dystrophy, that exhibits progressive pathological changes due to abnormalities in a distinct genetic entity (98), suggests itself for a biochemical analysis using comparative proteomic approaches (99). However, as outlined by LeBihan and coworkers (28), the analysis of small muscle biopsies from genetically diverse human patients presents a technical challenge for the proper identification of valid biomarkers of muscle diseases. It is therefore an advantage to employ suitable animal models for the large-scale screening of novel disease markers of a neuromuscular disorder prior to studying human biopsy specimens with a high degree of interindividual differences (100). Once reliable biomarkers have been identified, for example by comparative chromatographical or 2-D gel electrophoretic screening of mouse models, simpler biochemical methods such as immunoblotting can then be used to characterise human biopsy material. Since differences in life history, life style, gender, age, nutrition and unrelated disease processes such as infections, can have a major impact on the muscle protein expression pattern in humans, this scientific approach is easier and more reliable. In the case of dystrophinopathy, the natural MDX mutant mouse is widely employed as an animal model which exhibits severe muscular degeneration in the diaphragm (101). Muscle fibres from the MDX mouse exhibit, in analogy to human muscular dystrophy, a primary genetic abnormality in the dystrophin isoform Dp427 (102), a concomitant reduction in the dystrophin-associated glycoprotein complex (103), drastically elevated levels of serum creatine kinase (104), segmental fibre necrosis (105), an increased susceptibility to osmotic shock (106), stretchinduced injury (107) and an abnormal excitation-contractionrelaxation cycle (108-110). This makes MDX muscles not only a suitable system to study novel therapeutic strategies, but also to identify new biomarkers of X-linked muscular 
dystrophy. In order to directly compare normal versus dystrophic MDX samples, conventional Hot-Coomassie and silver-staining in combination with 2-D spot pattern software analysis has been used $(34,56,81,82)$, as well as the more discriminatory fluorescence DIGE method (35).

Fig. 8 illustrates the silver-stained 2-D protein spot pattern of dystrophic MDX limb muscle fibres and Fig. 5B-G shows the comparative DIGE analysis of the MDX diaphragm muscle. Our recent studies $(34,35,56)$, in addition to the published work by Ge et al $(81,82)$ have established a reduction in adenylate kinase, calsequestrin and regucalcin and a concomitant increase in the small heat shock protein cvHSP in MDX fibres. The usefulness of the fluorescence tagging method is clearly apparent from the enlarged images of the 2-D spot representing the cytosolic $\mathrm{Ca}^{2+}$-binding protein regucalcin. While the comparison of the large protein gels in Fig. 5B-D does not show major differences in the overall spot pattern between normal and dystrophic diaphragm fibres, fluorescence images focusing on the area of 30-50 kDa and pI 4-6 demonstrate a drastic reduction in the regucalcin protein species with an approximate molecular mass of $33.9 \mathrm{kDa}$ and an estimated pI-value of 5.2 (Fig. 5E-G). The DIGE technique resulted in the detection of approximately 2,400 individual 2-D diaphragm muscle protein spots (35), which makes this technique several fold more sensitive than comparative proteomics employing Hot-Coomassie or silver staining. A statistically significant decrease in the expression of 21 muscle proteins was be shown in the MDX diaphragm using the DIGE technique, which included dihydrolipoamide dehydrogenase, adenylate kinase, the Fbxo11-protein, and B-hemoglobin. In contrast, the density of 14 diaphragm proteins was drastically increased. This included cardiac and muscle myosin heavy chains, the heat shock proteins cvHSP and chaperonin, as well as aldehyde reductase, desmin, and vimentin (35). Hence, the lack of plasmalemmal integrity appears to cause a generally perturbed protein expression pattern in dystrophic muscle fibres, which might initiate severe disturbances of ion homeostasis and signal transduction mechanisms $(58,96,97)$. Notably, the observed upregulation of the small heat shock protein cvHSP suggests that increased expression of stress elements seems to be an essential cellular response in the dystrophic phenotype (111). The pharmacological induction of muscle-specific heat shock proteins could therefore represent a novel therapeutic strategy approach to reverse the muscle degeneration process in inherited neuromuscular disorders $(35,112)$ or support myoblast transfer approaches (113).

\section{Proteomic profiling of sarcopenia of old age}

Although muscle aging can be partially prevented by regular exercise and proper nutritional support, the progressive loss of skeletal muscle mass and strength is one of the most striking features of the senescent organism (44-46). The all-embracing term for the age-related muscle-wasting syndrome has now been generally accepted as being sarcopenia of old age (45). While the majority of aging humans experience, at least initially, a relatively mild form of sarcopenia, severe forms of age-dependent muscular atrophy present serious muscle pathology (44). With the drastic increase in the average life expectancy in developed countries, clinical sarcopenia in the very old may lead to frailty and pronounced functional impairment and therefore represents a major challenge to health services (46). Aging can be defined as the progressive loss or function of a biological system, which is accompanied by decreasing fertility and increasing mortality. Biological aging has to be considered as a natural progressive decline in body systems. It represents a fundamental biological process that seems to be intrinsic to almost all cellular systems, including muscle tissues.

The role of aging in nature and the evolutionary mechanisms that are associated with the senescence process are poorly understood but intensively debated. The major hypotheses of aging include four main ideas, i.e. the 'programmed senescence' hypothesis, the 'mutation accumulation' hypothesis, the 'antagonistic pleiotropy' hypothesis and the 'disposable soma' hypothesis (114). In order to understand the functional decline in muscle strength in the elderly, these suggested biological mechanisms might be valid starting points to initiate proteomic profiling studies to elucidate the biochemical mechanisms that lead to senescent muscular atrophy. Possibly, genes that specifically trigger the aging process have evolved in order to limit population size. Acceleration of the turnover of generations may then aid in the adaptation of organisms to drastically changed environmental conditions. In contrast, the so-called 'selection shadow' at old age may permit an accumulation of deleterious mutations causing biological aging. This might trigger for example oxidative stress in the peripheral nervous system, thereby affecting the innervation pattern of skeletal muscles. Genetic pleiotropy is the production of two or more, apparently unrelated, biological effects by a single gene. If pleiotropic genes benefit organisms early in life, they should be favoured by evolutionary selection. If the same genes have negative effects at later stages, they may cause molecular senescence, such as muscle wasting.

For an individual organism, the metabolic resources for biological maintenance and cellular repair are limited. The overall evolutionary pressure on a specific biological system is therefore probably limited to keep it in proper conditions for optimum survival (114). Thus, senescence may be a result of a bioenergetic trade-off between somatic cells versus germ line maintenance. In biological terms, there has to be an optimum distribution of limited metabolic resources between somatic maintenance and reproduction. Aging in animals appears to occur almost exclusively in protected environments and not under natural conditions. Comparative studies of wild and domesticated animal species suggest that the recent dramatic increase in human longevity is probably closely connected to improved hygiene, better shelter from exposure thereby preventing thermogenesis, vastly superior nutrition, better general health care and unprecedented advances in medical and pharmacological treatments of major diseases, especially infectious disorders (114). If this idea reflects correctly the biological phenomena of human aging, disorders of senility such as sarcopenia may be classified as clinical artifacts that would not occur under natural conditions (115). This hypothesis is obviously controversial and certainly covers up the fact that aging is a fundamental biological process, in the same way as fertilization or cellular differentiation. 
Independent from this purely biological perspective of the role of aging during human evolution, sarcopenia is a real and very serious clinical problem in the aging population and warrants large-scale biochemical analyses such as MS-based proteomics.

In developing new treatment strategies for counteracting age-related muscle degeneration, it is of central importance to analyse the molecular pathogenesis of the entire aging process (116). This would include epidemiological, clinical, histological, anatomical, genetic, molecular biological, cell biological, physiological and biochemical approaches (117). Comparative proteomics suggests itself as the initial method of choice, since it can be employed in an analytical highthroughput mode and be used to determine potential changes in protein expression levels at the entire protein complement level. This gives proteomic approaches a great advantage over more restrictive biochemical investigations of the past, which have focused on particular types of proteins or individual pathways that may be involved in fibre degeneration. In conjunction with transcriptomics, proteomic aging research has the real potential to make a decisive step forward in our understanding of the cellular aging process and may elucidate the molecular mechanisms that underlie the pathological changes that lead to age-dependent functional impairments (118-121). However, the rationalisation of the pathobiochemical hierarchy within intrinsic hazards that lead to cellular aging will be extremely difficult. Complex biological processes are associated with sarcopenia, such as oxidative stress, impaired cellular repair, mutation accumulation and genetic degeneration. Proteomic profiling can only be a starting point to identify new biomarkers of the age-dependent decline in muscle strength. Once novel disease proteins have been established, only a detailed biochemical, physiological and cell biological characterisation can define their exact role in sarcopenia. Initial findings from an ongoing long-term proteomic study on the protein composition of aged human muscles have demonstrated that approximately $60 \%$ of fibre protein species are shared between individuals (16). The remaining proteins are believed to represent inter-individual differences and these molecular adaptations may reflect differences that decisively determine the degree and time line of the muscle aging process. These kinds of detailed comparative studies with large cohorts of individual muscle proteomes may lay the foundation for establishing bio-gerontology as one of the most important fields in modern biology and clarify the role of senescence in nature.

Since the age-associated loss of muscle mass and its functional consequences are due to a variety of molecular and cellular changes, and such complex pathological changes cannot be studied in their entirety by conventional biochemistry, proteomic screening may be the best way to uncover new protein factors that are primarily involved in sarcopenia. Many physiological, biochemical and cellular abnormalities have already been described to be associated with muscle aging, whereby it is difficult to decipher if a molecular pathological hierarchy and/or interdependence between the various metabolic insults exist $(116,117)$. The most obvious abnormalities in aged skeletal muscle fibres are a general loss of active motor units, a shift to a slower twitching fibre type and progressive denervation (122-124). As reviewed by Carlson et al (125), the consequences of natural muscle aging and experimental denervation are very similar on the cell biological level. Hence, pathological changes in the peripheral nervous system may play a more important role in age-related muscle wasting, as for example intrinsic fibre changes due to a true muscle-specific defect. Since gene expression and protein isoform concentration patterns in skeletal muscle are greatly influenced by fibre loading and neuromuscular activity, this idea is a valid hypothesis to explain certain aspects of sarcopenia. A strong indicator that partial denervation or abnormal neuronal transmission plays a central role in aging muscle pathology is presented by the biochemical analysis of experimentallystimulated aged fibres $(126,127)$. The biological potential of young versus old muscle to adapt to a physiological challenge, such as chronic low-frequency stimulation, is very comparable. The alterations in the metabolic enzyme profile of conditioned young and old skeletal muscles did not show a significant difference (127). Thus, skeletal muscles themselves appear not to age drastically, but the nerve-muscle connection is intrinsically involved in the fate of a motor unit-associated group of fibres. In addition, an altered equilibrium of growth factors and hormones important for the maintenance of proper muscle function, modified gas and metabolite exchange rates due to decreased capillarisation, disturbed physiological ion handling leading to abnormal ion homeostasis, decreased protein synthesis of contractile and regulatory muscle proteins, a general progressive decline in energy intake, specific abnormalities in energy supply to fibres based on mitochondrial alterations, extensive oxidative stress, increased triggering of apoptotic pathways, abnormal metabolic regulation and a decreased availability of satellite cells, have all been implicated in rendering muscles more susceptible to sarcopenia (128-136).

In human muscle aging, the loss of biological integrity and metabolic homeostasis shows considerable inter-individual differences. Although the detailed study of these biological variations may be helpful in determining alternative pathways to adapt to intrinsic and/or extrinsic cellular hazards, the enormous complexity of changes may make it very difficult to properly differentiate between primary and secondary effects. Thus, the initial usage of established inbred animal models may be the best way to identify new biomarkers by proteomics and then use specific probes, such as monoclonal antibodies, to investigate the fate of these proteins in more detail in aging human skeletal muscles. Recent proteomic studies with aged rat muscle tissues show that this is a valid approach. Schoeneich and co-workers $(84,85)$ showed that nitration of key muscle proteins may be involved in the functional decline of motor unit function. That the agedependent nitration of muscle proteins is deleterious to fibre physiology has been shown for the relaxation-inducing $\mathrm{Ca}^{2+}$ ATPase of the sarcoplasmic reticulum (137). In analogy to these earlier biochemical studies, the proteomic profiling of aged muscle fibres revealed the nitration of essential metabolic enzymes, such as aldolase, enolase, glyceraldehyde-3-phosphate dehydrogenase, triosephosphate isomerase, succinate dehydrogenase and creatine kinase $(84,85)$. Since the constant exposure of fibres to high levels 
of nitric oxide and superoxide triggers the formation of peroxynitrate, nitration of tyrosine residues occurs in both young and old muscles. However, nitrated protein species appear to accumulate at an accelerated rate in senescent fibres, which may be due to more nitration and/or drastically reduced rates of protein turnover in aged skeletal muscles. The increased presence of nitrotyrosine in muscle proteins is usually associated with a decline in biological activity and could therefore play a central role in age-dependent dysfunction of muscle.

Piec et al (87) and Gelfi et al (88) have recently performed a proteomic survey of aged rat and human muscle, respectively, which identified the differential expression of various muscle components. Aged fibres exibited a severely disturbed protein expression pattern including a modified concentration of contractile elements such as myosin light chains, actin and troponins, the cytoskeletal proteins desmin and tubulin, and various regulatory proteins. This shows that aging has a profound effect on many key processes in muscle, including the functioning and regulation of the contractile apparatus, as well as the cytoskeletal network.

\section{Proteomics of skeletal muscle transformation}

Slow versus fast muscle fibres may exhibit different degrees of susceptibility to pathological insults and fibre type shifting has been shown to be associated with certain degenerative muscle disorders. For example, fast fibres are believed to be earlier affected in muscular dystrophy and changes in fibre type composition appear to be a feature of age-induced muscle wasting (43). Under normal physiological conditions, adaptations to changed neuromuscular activity also trigger subtle fibre type shifting $(19,20)$. Traumatic injuries to muscles initiate the proliferation of the fibre-specific stem cell pool, the muscle satellite cell population. The subsequent motor neuron activity dictates the differentiation pattern of the newly fused fibres, forming motor units between the nerve and its associated group of multi-nucleated muscle cells (17). Therefore, it is crucial to understand the molecular and cellular mechanisms that underlie the formation and maintenance of the differently contracting fibres. An ideal experimental model system for studying the graded responses of skeletal muscles to enhanced neuromuscular activity under conditions of maximum activation is presented by external chronic low-frequency stimulation. As reviewed by Pette and Staron (22), the physiological and biochemical characterisation of this system has elucidated three main cellular processes during the fast-to-slow transition period. Firstly, a certain degree of fibre transformation is due to true trans-differentiation from a fast-twitching to a slower-contracting fibre phenotype. Secondly, satellite cells are recruited and differentiate according to the changed pattern of innervation. Thirdly, cellular destruction and regeneration occurs involving especially the fastest contracting glycolytic fibre population. The final physiological results of long-term low-frequency stimulation are muscles that exhibit smaller caliber cells with an elevated aerobic-oxidative capacity and a higher resistance to fatigue (20). Physiologically, the most striking feature of transformed fibres is a drastic increase in the half-relaxation time and the time-to-peak twitch tension (138). Stimulation-
TA SOL

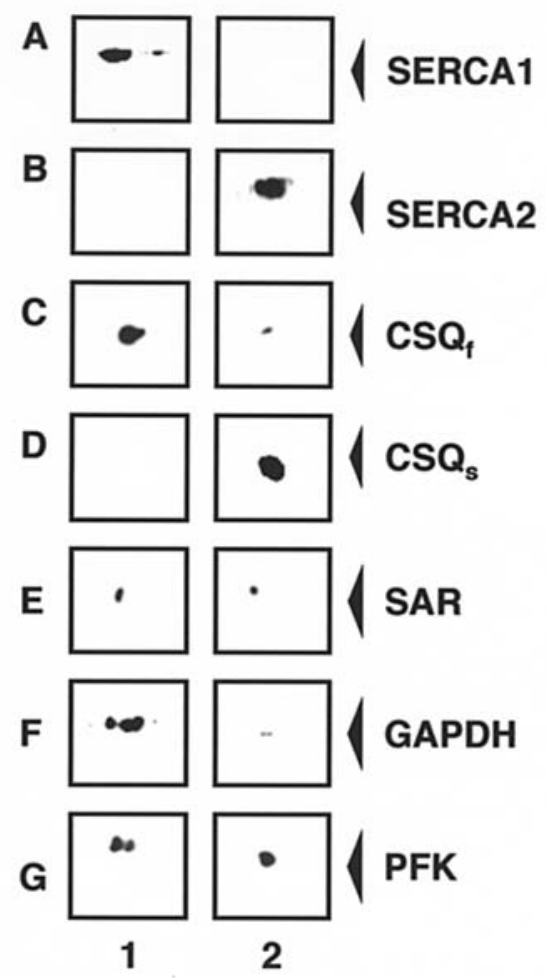

Figure 9. Immunoblotting survey of biomarkers of the fast and slow muscle phenotype. Shown are 2-D immunoblots, focusing on the area of immunodecoration, that have been labeled with antibodies to the fast-twitch SERCA1 isoform of the sarcoplasmic reticulum $\mathrm{Ca}^{2+}$-ATPase (A), the slowtwitch SERCA2 isoform of the sarcoplasmic reticulum $\mathrm{Ca}^{2+}$-ATPase (B), the fast-twitch $\mathrm{CSQ}_{\mathrm{f}}$ isoform of the terminal cisternae $\mathrm{Ca}^{2+}$-binding protein calsequestrin $(\mathrm{C})$, the slow-twitch $\mathrm{CSQ}_{\mathrm{s}}$ isoform of the terminal cisternae $\mathrm{Ca}^{2+}$-binding protein calsequestrin (D), the $\mathrm{Ca}^{2+}$-shuttle element sarcalumenin (SAR) of the sarcoplasmic reticulum (E), the enzyme glyceraldehyde-phosphate dehydrogenase (GAPDH) (F) and phosphofructo-kinase $(\mathrm{PFK})(\mathrm{G})$. Lanes 1 and 2 represent extracts from the rabbit tibialis anterior (TA) and soleus (SOL) muscle, respectively.

induced fibre type shifting is also reflected by alterations in the combinatorial isoform expression pattern of key muscle proteins, including contractile elements such as the myosin heavy chains, ion-regulatory proteins such as $\mathrm{Ca}^{2+}$-pumps, $\mathrm{Ca}^{2+}$-channels and $\mathrm{Ca}^{2+}$-binding proteins, and various metabolic enzymes, transporters, signaling elements and receptors $(22,139-141)$.

The traditional method of investigating fibre type shifting on the biochemical level is to focus on individual protein species, metabolic pathways or physiological processes $(18-20,22)$. Since this is an extremely laborious approach that lacks a comprehensive dimension, comparative proteomics suggests itself as the method of choice for future muscle transformation studies. Because MS methodologies in combination with suitable dye staining techniques can determine the fate of hundreds to thousands of muscle proteins in one experimental step, the proteomic profiling of electrostimulated fibres promises exiting new insights into the biology of muscle differentiation. In addition to many other muscle research groups involved in muscle proteomics (Table I), our laboratory is currently involved in the systematic identification and cataloging of muscle proteins that can be 
employed as biomarkers of fibre type changes. Over the last few decades it has been established that skeletal muscles are highly versatile and extremely plastic, so that their contractile properties are highly adaptable to changed functional demands (18). The first comprehensive proteomic analysis of fast versus transformed fibres has confirmed that enhanced contractile activity due to chronic low-frequency stimulation causes an array of functional, structural and metabolic alterations in order to adapt to altered physiological requirements (54). The differential protein expression pattern in fast versus slow fibres shown in the 2-D immunoblotting survey in Fig. 9 was observed to a comparable degree in unstimulated versus transformed fibres. In agreement with the proteomic profiling of fast versus slow muscle populations (66-69), the immunoblotting survey of biomarkers of the fast and slow muscle phenotype presented here demonstrates that the fast and slow isoforms of the sarcoplasmic reticulum $\mathrm{Ca}^{2+}$-ATPase and the terminal cisternae $\mathrm{Ca}^{2+}$-binding protein calsequestrin are reliable indicators of fibre type distribution. In addition, the expression of enzymes such as glyceraldehyde-phosphate dehydrogenase is a good marker for shifts from a glycolytic to a more oxidative metabolism (Fig. 9).

The recent proteomic profiling of chronic low-frequencystimulated tibialis anterior muscles using conventional Coomassie staining of 2-D gels revealed that 16 major muscle protein species underwent a drastic alteration in their expression levels during the fast-to-slow transition process (54). This agrees with the drastic alterations in protein expression patterns between unstimulated versus electrostimulated fast muscles as illustrated by fluorescence DIGE analysis (Fig. 5A). Changes in skeletal muscle bio-markers suggest that the transformation of easily fatiguing white fibres into fatigue-resistant red fibres is associated with a conversion of the contractile apparatus to isoforms with slower twitch characteristics, the optimum utilization of free fatty acids via increased albumin transportation, a rearrangement of the creatine kinase isozyme pattern for enhanced mitochondrial activity, an increased availability of oxygen for aerobic metabolism via myoglobin transport, and the up-regulation of stress proteins for stabilising myofibrillar components with chaperones (54). A striking finding of the proteomic strategy was a drastic increase in the abundance of albumin and the mitochondrial marker enzyme creatine kinase. This indicates that the enhanced transportation of fatty acids and increased mitochondrial metabolism are important prerequisites for successful fast-to-slow fibre transformation. A reduction in the density of glycolytic enzymes, such as enolase and aldolase, and a concomitant increase in the oxygen-carrier myoglobin clearly argues in favour of a shift from a glycolysis-dominated bioenergetic process to more oxidative metabolism in conditioned muscles. Changes in the contractile apparatus were reflected by distinct switches in the fast and slow isoforms of troponin and myosin light chain (54). Hence, the proteomic profiling of conditioned muscles has clearly shown that chronic electro-stimulation changes the isoform expression pattern of the contractile machinery, the regulatory excitation-contraction coupling apparatus, the luminal and cytosolic ion homeostasis complex and metabolic pathways. Future experiments using the DIGE technique with a higher sensitivity will be employed to refine these results and will hopefully lead to a better understanding of fibre type shifting in normal and pathological muscle fibres.

\section{Future perspectives}

For future studies into the cause of age-related or inherited muscle diseases, proteomics is an excellent way of determining an initial picture of differential protein expression patterns in normal versus diseased tissues (142). Although current protein chemical separation techniques do not achieve a complete presentation of all protein species from a given proteome, the near-to-total proteome approach is the most suitable and the most advanced biotechnological tool available to determine changes leading to skeletal muscle pathologies. Intraproteomics analysis is an excellent approach to evaluating abnormal protein complex formation. Despite the fact that homogenous preparations of monomeric proteins or peptides can often perform enzymatic reaction cycles, under in vivo conditions most biological macromolecules do not exist in isolation but act as multi-functional entities within supra-molecular assemblies. Thus, if one defines individual peptide species as the basic units of an ensemble of proteins related to a genome, then heterogeneous protein complexes actually form the functional units of biochemistry and cell biology. This gives intraproteomic studies into the quaternary structure of supramolecular complexes a central place in modern biochemical research. If due to the complexity of mammalian cells, homogenization technology does not result in the preparation of suitable extracts, then subproteomics is the method of choice. It is, however, important to be aware of the introduction of artifacts during subcellular fractionation protocols. Hence, the future success of subproteomic approaches will depend on the development of improved subcellular fractionation techniques, advances in protein separation methods, a better combination of quick assays for protein identification and the establishment of faster protein-protein interaction assays.

\section{Acknowledgements}

Research was supported by an SFI investigator programme grant (no. 04/IN3/B614) from Science Foundation Ireland, a network grant from the European Commission (no. RTN22001-00337), and equipment grants from the Irish Health Research Board (nos. HRB-EQ/2003/3, HRB-EQ/2004/2). The authors thank Dr Dirk Pette (Professor emeritus, University of Konstanz, Germany) and Dr Harald Jockusch (Professor emeritus, University of Bielefeld, Germany) for their continuous support of our proteomics research projects involving transformed and dystrophic fibres.

\section{References}

1. Mann M, Hendrickson RC and Pandey A: Analysis of proteins and proteomes by mass spectrometry. Annu Rev Biochem 70: 437-473, 2001.

2. Ferguson PL and Smith RD: Proteome analysis by mass spectrometry. Annu Rev Biophys Biomol Struct 32: 399-424, 2003.

3. Aebersold $\mathrm{R}$ and Mann M: Mass spectrometry-based proteomics. Nature 422: 198-207, 2003. 
4. Lin D, Tabb DL and Yates JR III: Large-scale protein identification using mass spectrometry. Biochim Biophys Acta 1646: 1-10, 2003.

5. de Hoog CL and Mann M: Proteomics. Annu Rev Genomics Hum Genet 5: 267-293, 2004.

6. Yan W and Chen SS: Mass spectrometry-based quantitative proteomic profiling. Brief Funct Genomic Proteomic 4: 27-38, 2005.

7. Ong SE and Mann M: Mass spectrometry-based proteomics turns quantitative. Nat Chem Biol 1: 252-262, 2005.

8. Guerrera IC and Kleiner O: Application of mass spectrometry in proteomics. Biosci Rep 25: 71-93, 2005.

9. Domon B and Aebersold R: Mass spectrometry and protein analysis. Science 312: 212-217, 2006

10. Gorg A, Weiss W and Dunn MJ: Current two-dimensional electrophoresis technology for proteomics. Proteomics 4: 3665-3685, 2004.

11. Wu CC and Yates JR III: The application of mass spectrometry to membrane proteomics. Nat Biotechnol 21: 262-267, 2003.

12. Mann $M$ and Jensen ON: Proteomic analysis of posttranslational modifications. Nat Biotechnol 21: 255-261, 2003.

13. Seo J and Lee KJ: Post-translational modifications and their biological functions: proteomic analysis and systematic approaches. J Biochem Mol Biol 37: 35-44, 2004.

14. Jensen ON: Modification-specific proteomics: characterization of post-translational modifications by mass spectrometry. Curr Opin Chem Biol 8: 33-41, 2004

15. van den Heuvel LP, Farhoud MH, Wevers RA, van Engelen BG and Smeitink JA: Proteomics and neuromuscular diseases: theoretical concept and first results. Ann Clin Biochem 40: 9-15, 2003.

16. Cobon GS, Verrills N, Papakostopoulos P, Eastwood H and Linnane AW: The proteomics of ageing. Biogerontology 3: 133-136, 2002

17. Engel AG and Franzini-Armstrong C: The scientific basis of myology. In: Basic and Clinical Myology. Vol. 1, McGraw-Hill Inc., New York, pp1-735, 1994.

18. Pette D: Historical perspectives: plasticity of mammalian skeletal muscle. J Appl Physiol 90: 1119-1124, 2001.

19. Pette D: The adaptive potential of skeletal muscle fibers. Can J Appl Physiol 27: 423-448, 2002.

20. Fluck M and Hoppeler H: Molecular basis of skeletal muscle plasticity - from gene to form and function. Rev Physiol Biochem Pharmacol 146: 159-216, 2003.

21. Lu DX, Huang SK and Carlson BM: Electron microscopic study of long-term denervated rat skeletal muscle. Anat Rec 248: 355-365, 1997.

22. Pette D and Staron RS: Transitions of muscle fiber phenotypic profiles. Histochem Cell Biol 115: 359-372, 2001.

23. Carlson BM, Billington L and Faulkner JA: Studies on the regenerative recovery of long-term denervated muscle in rats. Restor Neurol Neurosci 10: 77-84, 1996.

24. Goldspink G: Gene expression in muscle in response to exercise. J Muscle Res Cell Motil 24: 121-126, 2003.

25. Ohira Y, Yoshinaga T, Nomura T, Kawano F, Ishihara A, Nonaka I, Roy RR and Edgerton VR: Gravitational unloading effects on muscle fiber size, phenotype and myonuclear number. Adv Space Res 30: 777-781, 2002.

26. Isfort RJ: Proteomic analysis of striated muscle. J Chromatogr B 771: 155-165, 2002.

27. Tuzun E, Sharp AJ, Bailey JA, Kaul R, Morrison VA, Pertz LM, Haugen E, Hayden H, Albertson D, Pinkel D, Olson MV and Eichler EE: Fine-scale structural variation of the human genome. Nat Genet 37: 727-732, 2005.

28. LeBihan MC, Tarelli E and Coulton GR: Evaluation of an integrated strategy for proteomic profiling of skeletal muscle. Proteomics 4: 2739-2753, 2004

29. Towbin H, Staehelin T and Gordon J: Immunoblotting in the clinical laboratory. J Clin Chem Clin Biochem 27: 495-501, 1989.

30. Bienvenut WV, Deon C, Pasquarello C, Campbell JM Sanchez JC, Vestal ML and Hochstrasser DF: Matrix-assisted laser desorption/ionization-tandem mass spectrometry with high resolution and sensitivity for identification and characterization of proteins. Proteomics 2: 868-876, 2002.

31. Webster J and Oxley D: Peptide mass fingerprinting: protein identification using MALDI-TOF mass spectrometry. Methods Mol Biol 310: 227-240, 2005.

32. Celis JE, Honore B, Bauw G and Vandekerckhove J: Comprehensive computerized 2D gel protein databases offer a global approach to the study of the mammalian cell. Bioessays 12: 93-97, 1990.
33. Sanchez JC, Chiappe D, Converset V, Hoogland C, Binz PA, Paesano S, Appel RD, Wang S, Sennitt M, Nolan A, Cawthorne MA and Hochstrasser DF: The mouse SWISS2DPAGE database: a tool for proteomic study of diabetes and obesity. Proteomics 1: 136-163, 2001.

34. Doran P, Dowling P, Donoghue P, Buffini M and Ohlendieck K Reduced expression of regucalcin in young and aged $\mathrm{mdx}$ diaphragm indicates abnormal cytosolic calcium handling in dystrophin-deficient muscle. Biochim Biophys Acta 1764: 773-785, 2006.

35. Doran P, Martin G, Dowling P, Jockusch H and Ohlendieck K: Proteome analysis of the dystrophin-deficient MDX diaphragm reveals a drastic increase in the heat shock protein cvHSP. Proteomics 6: 4610-4621, 2006.

36. Henzel WJ, Bourell JH and Stults JT: Analysis of protein digests by capillary high-performance liquid chromatography and on-line fast atom bombardment mass spectrometry. Anal Biochem 187: 228-233, 1990.

37. Henzel WJ, Watanabe C and Stults JT: Protein identification: the origins of peptide mass fingerprinting. J Am Soc Mass Spectrom 14: 931-942, 2003.

38. Burlingame AL, Carr SA and Baldwin MA: Mass Spectrometry in Biology and Medicine. Humana Press, Totowa, NJ, pp1-577, 2000.

39. Pennington SR and Dunn MJ: Proteomics: From Protein Sequence to Function. Springer Verlag, New York, pp1-313, 2001.

40. Westermeier $\mathrm{R}$ and Naven T: Proteomics in Practice. WileyVCH Verlag, Weinheim, pp1-318, 2002

41. Walker JM: Proteomics Protocols Handbook. Humana Press, Tototowa, NJ, pp1-988, 2005.

42. Jarrold B, DeMuth J, Greis K, Burt T and Wang F: An effective skeletal muscle prefractionation method to remove abundant structural proteins for optimized two-dimensional gel electrophoresis. Electrophoresis 26: 2269-2278, 2005.

43. Engel AG and Franzini-Armstrong C: The scientific basis of myology. In: Basic and Clinical Myology. Vol. 2, McGraw-Hill Inc., New York, pp1130-1937, 1994

44. Melton LJ III, Khosla S, Crowson CS, O'Connor MK, O'Fallon WM and Riggs BL: Epidemiology of sarcopenia. J Am Geriatr Soc 48: 625-630, 2000.

45. Morley JE, Baumgartner RN, Roubenoff R, Mayer J and Nair KS Sarcopenia. J Lab Clin Med 137: 231-243, 2001

46. Greenlund LJS and Nair KS: Sarcopenia - consequences, mechanisms, and potential therapies. Mech Ageing Dev 124: 287-299, 2003.

47. Froemming GR and Ohlendieck K: The role of ion-regulatory membrane proteins of excitation-contraction coupling and relaxation in inherited muscle diseases. Front Biosci 6: D65-D74, 2001.

48. Murray BE, Froemming GR, Maguire PB and Ohlendieck K: Excitation-contraction-relaxation cycle: Role of $\mathrm{Ca}^{2+}$-regulatory membrane proteins in normal, stimulated and pathological skeletal muscle fibres (Review). Int J Mol Med 1: 677-697, 1998.

49. Ohlendieck K: Malignant hyperthermia: a pharmacogenetic disease of excitation-contraction coupling. Curr Trends Neurol 1: 101-108, 2005.

50. Unlu M, Morgan ME and Minden JS: Difference gel electrophoresis: a single gel method for detecting changes in protein extracts. Electrophoresis 18: 2071-2077, 1997.

51. Unlu M: Difference gel electrophoresis. Biochem Soc Trans 27: 547-549, 1999.

52. Tonge R, Shaw J, Middleton B, Rowlinson R, Rayner S, Young J, Pognan F, Hawkins E, Currie I and Davison M: Validation and development of fluorescence two-dimensional differential gel electrophoresis proteomics technology. Proteomics 1: 377-396, 2001.

53. Marouga R, David S and Hawkins E: The development of the DIGE system: 2D fluorescence difference gel analysis technology. Anal Bioanal Chem 382: 669-678, 2005.

54. Donoghue $\mathrm{P}$, Doran $\mathrm{P}$, Dowling $\mathrm{P}$ and Ohlendieck K: Differential expression of the fast skeletal muscle proteome following chronic low-frequency stimulation. Biochim Biophys Acta 1752: 166-176, 2005.

55. Pette D and Staron RS: Cellular and molecular diversities of mammalian skeletal muscle fibers. Rev Physiol Biochem Pharmacol 116: 1-76, 1990.

56. Doran P, Dowling P, Lohan J, McDonnell K, Poetsch S and Ohlendieck K: Subproteomics analysis of $\mathrm{Ca}^{2+}$-binding proteins demonstrates decreased calsequestrin expression in dystrophic mouse skeletal muscle. Eur J Biochem 271: 3943-3952, 2004. 
57. Froemming GR and Ohlendieck K: Native skeletal muscle dihydropyridine receptor exists as a supramolecular triad complex. Cell Mol Life Sci 58: 312-320, 2001.

58. Culligan KG, Mackey AJ, Finn DM, Maguire PB and Ohlendieck K: Role of dystrophin isoforms and associated proteins in muscular dystrophy (Review). Int J Mol Med 2: 639-648, 1998.

59. Froemming GR, Murray BE and Ohlendieck K: Selfaggregation of triadin in the sarcoplasmic reticulum of rabbit skeletal muscle. Biochim Biophys Acta 1418: 197-205, 1990.

60. Yan JX, Harry RA, Wait R, Welson SY, Emery PW, Preedy V and Dunn MJ: Separation and identification of rat skeletal muscle proteins using two-dimensional gel electrophoresis and mass spectrometry. Proteomics 1: 424-434, 2001.

61. Bouley J, Chambon C and Picard B: Mapping of bovine skeletal muscle proteins using two-dimensional gel electrophoresis and mass spectrometry. Proteomics 4: 1811-1824, 2004.

62. Chaze T, Bouley J, Chambon C, Barboiron C and Picard B: Mapping of alkaline proteins in bovine skeletal muscle. Proteomics 6: 2571-2575, 2006.

63. Gelfi C, De Palma S, Cerretelli P, Begum S and Wait R: Twodimensional protein map of human vastus lateralis muscle. Electrophoresis 24: 286-295, 2003.

64. Capitanio D, Vigano A, Ricci E, Cerretelli P, Wait R and Gelfi C: Comparison of protein expression in human deltoideus and vastus lateralis muscles using two-dimensional gel electrophoresis. Proteomics 5: 2577-2586, 2005.

65. Li ZB, Lehar M, Braga N, Westra W, Liu LH and Flint PW: Study of human laryngeal muscle protein using twodimensional electrophoresis and mass spectrometry. Proteomics 3: 1325-1334, 2003.

66. Kim NK, Joh JH, Park HR, Kim OH, Park BY and Lee CS: Differential expression profiling of the proteomes and their mRNAs in porcine white and red skeletal muscles. Proteomics 4: 3422-3428, 2004.

67. Le Bihan MC, Hou Y, Harris N, Tarelli E and Coulton GR: Proteomic analysis of fast and slow muscles from normal and kyphoscoliotic mice using protein arrays, 2-DE and MS. Proteomics 6: 4646-4661, 2006.

68. Okumura N, Hashida-Okumura A, Kita K, Matsubae M, Matsubara T, Takao T and Nagai K: Proteomic analysis of slow- and fast-twitch skeletal muscles. Proteomics 5: 2896-2906, 2006.

69. Gelfi C, Vigano A, De Palma S, Ripamonti M, Begum S, Cerretelli $\mathrm{P}$ and Wait R: 2-D protein maps of rat gastrocnemius and soleus muscles: a tool for muscle plasticity assessment. Proteomics 6: 321-340, 2006.

70. Forner F, Foster LJ, Campanaro S, Valle G and Mann M: Quantitative proteomic comparison of rat mitochondria from muscle, heart, and liver. Mol Cell Proteomics 5: 608-619, 2006.

71. Cieniewski-Bernard C, Bastide B, Lefebvre T, Lemoine J, Mounier Y and Michalski JC: Identification of O-linked Nacetylglucosamine proteins in rat skeletal muscle using twodimensional gel electrophoresis and mass spectrometry. Mol Cell Proteomics 3: 577-585, 2004.

72. Doherty MK, McLean L, Hayter JR, Pratt JM, Robertson DH, El-Shafei A, Gaskell SJ and Beynon RJ: The proteome of chicken skeletal muscle: changes in soluble protein expression during growth in a layer strain. Proteomics 4: 2082-2093, 2004.

73. Kislinger T, Gramolini AO, Pan Y, Rahman K, MacLennan DH and Emili A: Proteome dynamics during $\mathrm{C} 2 \mathrm{C} 12$ myoblast differentiation. Mol Cell Proteomics 4: 887-901, 2005.

74. Takahashi $\mathrm{M}$ and Kubota S: Exercise-related novel gene is involved in myoblast differentiation. Biomed Res 26: 79-85, 2005.

75. Bouley J, Meunier B, Chambon C, De Smet S, Hocquette JF and Picard B: Proteomic analysis of bovine skeletal muscle hypertrophy. Proteomics 5: 490-500, 2005

76. Kjaersgard IV, Norrelykke MR and Jessen F: Changes in cod muscle proteins during frozen storage revealed by proteome analysis and multivariate data analysis. Proteomics 6: 1606-1618, 2006.

77. Martin SA, Vilhelmsson O, Medale F, Watt P, Kaushik S and Houlihan DF: Proteomic sensitivity to dietary manipulations in rainbow trout. Biochim Biophys Acta 1651: 17-29, 2003.

78. Gajendran N, Frey JR, Lefkovits I, Kuhn L, Fountoulakis M, Krapfenbauer K and Brenner HR: Proteomic analysis of secreted muscle components: search for factors involved in neuromuscular synapse formation. Proteomics 2: 1601-1615, 2002.
79. Isfort RJ, Wang F, Greis KD, Sun Y, Keough TW, Farrar RP, Bodine SC and Anderson NL: Proteomic analysis of rat soleus muscle undergoing hindlimb suspension-induced atrophy and reweighting hypertrophy. Proteomics 2: 543-550, 2002.

80. Isfort RJ, Wang F, Greis KD, Sun Y, Keough TW, Bodine SC and Anderson NL: Proteomic analysis of rat soleus and tibialis anterior muscle following immobilization. J Chromatogr B Anal Technol Biomed Life Sci 769: 323-332, 2002.

81.Ge Y, Molloy MP, Chamberlain JS and Andrews PC: Proteomic analysis of mdx skeletal muscle: Great reduction of adenylate kinase 1 expression and enzymatic activity. Proteomics 3: 1895-1903, 2003.

82. Ge Y, Molloy MP, Chamberlain JS and Andrews PC: Differential expression of the skeletal muscle proteome in $\mathrm{mdx}$ mice at different ages. Electrophoresis 25: 2576-2585, 2004.

83. De Palma S, Morandi L, Mariani E, Begum S, Cerretelli P, Wait R and Gelfi C: Proteomic investigation of the molecular pathophysiology of dysferlinopathy. Proteomics 6: 379-385, 2006.

84.Kanski J, Alterman MA and Schoneich C: Proteomic identification of age-dependent protein nitration in rat skeletal muscle. Free Radic Biol Med 35: 1229-1239, 2003.

85. Kanski J, Hong SJ and Schoneich C: Proteomic analysis of protein nitration in aging skeletal muscle and identification of nitrotyrosine-containing sequences in vivo by nanoelectrospray ionization tandem mass spectrometry. J Biol Chem 280: 24261-24266, 2005.

86. Chang J, Van Remmen H, Cornell J, Richardson A and Ward WF: Comparative proteomics: characterization of a twodimensional gel electrophoresis system to study the effect of aging on mitochondrial proteins. Mech Ageing Dev 124: 33-41, 2003.

87. Piec I, Listrat A, Alliot J, Chambon C, Taylor RG and Bechet D: Differential proteome analysis of aging in rat skeletal muscle. FASEB J 19: 1143-1145, 2005.

88. Gelfi C, Vigano A, Ripamonti M, Pontoglio A, Begum S, Pellegrino MA, Grassi B, Bottinelli R, Wait R and Cerretelli P: The human muscle proteome in aging. J Proteome Res 5: 1344-1353, 2006.

89. Emery AE: The muscular dystrophies. Lancet 359: 687-695, 2002.

90. Ahn AH and Kunkel LM: The structural and functional diversity of dystrophin. Nat Genet 3: 283-291, 1993.

91. Cohn RD and Campbell KP: Molecular basis of muscular dystrophies. Muscle Nerve 23: 1456-1471, 2000.

92. Rando TA: Role of nitric oxide in the pathogenesis of muscular dystrophies: a 'two hit' hypothesis of the cause of muscle necrosis. Microsc Res Tech 55: 223-235, 2001.

93. Ohlendieck K: Towards an understanding of the dystrophinglycoprotein complex: linkage between the extracellular matrix and the subsarcolemmal membrane cytoskeleton. Eur J Cell Biol 69: 1-10, 1996.

94. Alderton JM and Steinhardt RA: Calcium influx through calcium leak channels is responsible for the elevated levels of calcium-dependent proteolysis in dystrophic myotubes. J Biol Chem 275: 9452-9460, 2000.

95. Alderton JM and Steinhardt RA: How calcium influx through calcium leak channels is responsible for the elevated levels of calcium-dependent proteolysis in dystrophic myotubes. Trends Cardiovasc Med 10: 268-272, 2000.

96. Ohlendieck K: The pathophysiological role of impaired calcium handling in muscular dystrophy. In: Molecular Mechanisms of Muscular Dystrophies. Winder SJ (ed). Landes Bioscience, Georgetown, TX, pp183-192, 2006.

97. Batchelor CL and Winder SJ: Sparks, signals and shock absorbers: how dystrophin loss causes muscular dystrophy. Trends Cell Biol 16: 198-205, 2006.

98. Winder SJ: Molecular Mechanisms of Muscular Dystrophies. Landes Bioscience, Georgetown, TX, pp1-233, 2006.

99. Dowling P, Doran P, Lohan J, Culligan K and Ohlendieck K: Naturally protected muscle phenotypes: Development of novel treatment strategies for Duchenne muscular dystrophy. Basic Appl Myol 14: 169-178, 2004.

100. Watchko JF, O'Day TL and Hoffman EP: Functional characteristics of dystrophic skeletal muscle: insights from animal models. J Appl Physiol 93: 407-417, 2002.

101. Stedman HH, Sweeney HL, Shrager JB, Maguire HC, Panettieri, RA, Petrof B, Narusawa M, Leferovich JM, Sladky JT and Kelly AM: The mdx mouse diaphragm reproduces the degenerative changes of Duchenne muscular dystrophy. Nature 352: 536-539, 1991. 
102. Sicinski P, Geng Y, Ryder-Cook AS, Barnard EA, Darlison MG and Barnard PJ: The molecular basis of muscular dystrophy in the mdx mouse: a point mutation. Science 244: 1578-1580, 1989.

103. Ohlendieck K and Campbell KP: Dystrophin-associated proteins are greatly reduced in skeletal muscle from mdx mice. J Cell Biol 115: 1685-1694, 1991.

104.Bulfield G, Silver WG, Wight PAL and Moore KJ: Xchromosome-linked muscular dystrophy (mdx) in the mouse. Proc Natl Acad Sci USA 81: 1189-1192, 1984.

105. Torres LFB and Duchen LW: The mutant mdx: inherited myopathy in the mouse. Brain 110: 269-299, 1987.

106. Menke A and Jockusch H: Decreased osmotic stability of dystrophin-less muscle cells from mdx mouse. Nature 349: 69-71, 1991.

107.Lynch GS, Rafael JA, Chamberlain JS and Faulkner JA: Contraction-induced injury to single permeabilized muscle fibers from $\mathrm{mdx}$, transgenic $\mathrm{mdx}$, and control mice. Am J Physiol Cell Physiol 279: C1290-C1294, 2000.

108. DeLuca A, Pierno S, Liantonio A, Cetrone M, Camerino C, Simonetti S, Papadia F and Camerino DC: Alteration of excitation-contraction coupling mechanism in extensor digitorum longus muscle fibres of dystrophic mdx mouse and potential efficacy of taurine. Br J Pharmacol 132: 1047-1054, 2001.

109. Culligan K, Banville N, Dowling P and Ohlendieck K: Drastic reduction of calsequestrin-like proteins and impaired calcium binding in dystrophic mdx muscle. J Appl Physiol 92: 435-445, 2002.

110.Dowling P, Doran P and Ohlendieck K: Drastic reduction of sarcalumenin in Dp427 (dystrophin of $427 \mathrm{kDa}$ )-deficient fibres indicates that abnormal calcium handling plays a key role in muscular dystrophy. Biochem J 379: 479-488, 2004.

111.Nishimura RN and Sharp FR: Heat shock proteins and neuromuscular disease. Muscle Nerve 32: 693-709, 2005.

112. Bornman L, Polla BS, Lotz BP and Gericke GS: Expression of heat-shock/stress proteins in Duchenne muscular dystrophy. Muscle Nerve 18: 23-31, 1995.

113. Bouchentouf M, Benabdallah BF and Tremblay JP: Myoblast survival enhancement and transplantation success improvement by heat-shock treatment in mdx mice. Transplantation 77 : 1349-1356, 2004.

114. Kirkwood TB and Austad SN: Why do we age? Nature 408: 233-238, 2000

115.Evans WJ: What is sarcopenia? J Gerontol 50A: 5-8, 1995.

116. Navarro A, Lopez-Cepero JM and Sanchez del Pino MJ: Skeletal muscle ageing. Front Biosci 6: 26-44, 2001.

117. Carmeli E, Coleman R and Reznick AZ: The biochemistry of aging muscle. Exp Gerontol 37: 477-489, 2002.

118. Toda T: Current status and perspectives of proteomics in aging research. Exp Gerontol 35: 803-810, 2000.

119. Martin GM: Some new directions for research on the biology of aging. Ann NY Acad Sci 908: 1-13, 2000.

120.Toda T: Proteome and proteomics for the research on protein alterations in aging. Ann NY Acad Sci 928: 71-78, 2001.

121. Schoneich C: Proteomics in gerontological research. Exp Gerontol 38: 473-481, 2003.

122. Larsson L and Ansved T: Effects of ageing on the motor unit. Prog Neurobiol 45: 397-458, 1995.

123. Luff AR: Age-associated changes in the innervation of muscle fibres and changes in the mechanical properties of motor units. Ann NY Acad Sci 854: 92-101, 1998.
124.Larsson L: The age-related motor disability: underlying mechanisms in skeletal muscle at the motor unit, cellular and molecular level. Acta Physiol Scand 163: S27-S29, 1998

125. Carlson BM: Denervation and the aging of skeletal muscle. Basic Appl Myol 14: 135-140, 2004.

126. Skorjanc D, Traub I and Pette D: Identical responses of fast muscle to sustained activity by low-frequency-stimulation in young and aging rats. J Appl Physiol 85: 437-441, 1998.

127. Pette D and Skorjanc D: Adaptive potentials of skeletal muscle in young and aging rats. Int J Sport Nutr Exerc Metab 11: S3-S8, 2001.

128. Squier TS and Bigelow DJ: Protein oxidation and agedependent alterations in calcium homeostasis. Front Biosci 5 504-526, 2000

129. Bua EA, McKiernan SH, Wanagat J, McKenzie D and Aiken JM: Mitochondrial abnormalities are more frequent in muscles undergoing sarcopenia. J Appl Physiol 92: 2617-2624, 2002.

130.Dirks A and Leeuwenburgh C: Apoptosis in skeletal muscle with aging. Am J Physiol 282: R519-R527, 2002.

131. Vandervoort AA and Symons TB: Functional and metabolic consequences of sarcopenia. Can J Appl Physiol 26: 90-101, 2001.

132. Roberts SB: Effects of aging on energy requirements and the control of food intake in men. J Gerontol 50A: 101-106, 1995.

133. Degens H: Age-related changes in the microcirculation of skeletal muscle. Adv Exp Med Biol 454: 343-348, 1998

134. Balagopal P, Rooyackers OE, Adey DB, Ades PA and Nair KS Effects of aging on in vivo synthesis of skeletal muscle myosin heavy-chain and sarcoplasmic protein in humans. Am J Physiol 273: E790-E800, 1997.

135. Ryan M and Ohlendieck K: Excitation-contraction uncoupling and sarcopenia. Basic Appl Myol 14: 141-154, 2004.

136. Renault V, Thornell LE, Eriksson PO, Butler-Browne G and Mouly V: Regenerative potential of human skeletal muscle during aging. Aging Cell 1: 132-139, 2002.

137. Viner RI, Ferrington DA, Williams TD, Bigelow DJ and Schoneich C: Protein modification during biological aging: selective tyrosine nitration of the SERCA2a isoform of the sarcoplasmic reticulum $\mathrm{Ca}^{2+}$-ATPase in skeletal muscle. Biochem J 340: 657-669, 1999.

138.Hicks A, Ohlendieck K, Gopel SO and Pette D: Early functional and biochemical adaptations to low-frequency stimulation of rabbit fast-twitch muscle. Am J Physiol 273: C297-C305, 1997.

139. Ohlendieck K: Changes in $\mathrm{Ca}^{2+}$-regulatory membrane proteins during the stimulation-induced fast-to-slow transition process. Basic Appl Myol 10: 99-106, 2000.

140. Ohlendieck K, Fromming GR, Murray BE, Maguire PB, Leisner E, Traub I and Pette D: Effects of chronic lowfrequency stimulation on $\mathrm{Ca}^{2+}$-regulatory membrane proteins in rabbit fast muscle. Pflugers Arch 438: 700-708, 1999.

141. Froemming GR, Murray BE, Harmon S, Pette D and Ohlendieck K: Comparative analysis of the isoform expression pattern of $\mathrm{Ca}^{2+}$-regulatory membrane proteins in fast-twitch, slow-twitch, cardiac, neonatal and chronic low-frequency stimulated muscle fibers. Biochim Biophys Acta 1466: 151-168, 2000.

142.Emery AE: Muscular dystrophy into the new millennium. Neuromusc Disord 12: 343-349, 2002. 